\title{
The Value of Sustained Ocean Observations for Sea Ice Predictions in the Barents Sea
}

\author{
Mitchell BushuK AND XiaOsong YANG \\ NOAA/Geophysical Fluid Dynamics Laboratory, Princeton, New Jersey, and University Corporation for Atmospheric Research, \\ Boulder, Colorado \\ MiCHAEL WINTON \\ NOAA/Geophysical Fluid Dynamics Laboratory, Princeton, New Jersey \\ RYM MSADEK \\ CNRS/CERFACS, CECI UMR 5318, Toulouse, France \\ MATTHEw HARRISON, ANTHONy Rosati, AND Rich GUDGEL \\ NOAA/Geophysical Fluid Dynamics Laboratory, Princeton, New Jersey
}

(Manuscript received 4 March 2019, in final form 11 July 2019)

\begin{abstract}
Dynamical prediction systems have shown potential to meet the emerging need for seasonal forecasts of regional Arctic sea ice. Observationally constrained initial conditions are a key source of skill for these predictions, but the direct influence of different observation types on prediction skill has not yet been systematically investigated. In this work, we perform a hierarchy of observing system experiments with a coupled global data assimilation and prediction system to assess the value of different classes of oceanic and atmospheric observations for seasonal sea ice predictions in the Barents Sea. We find notable skill improvements due to the inclusion of both sea surface temperature (SST) satellite observations and subsurface conductivitytemperature-depth (CTD) measurements. The SST data are found to provide the crucial source of interannual variability, whereas the CTD data primarily provide climatological and trend improvements. Analysis of the Barents Sea ocean heat budget suggests that ocean heat content anomalies in this region are driven by surface heat fluxes on seasonal time scales.
\end{abstract}

\section{Introduction}

Observations in the sparsely sampled polar regions are paramount to advancing understanding of highlatitude variability and change and improving polar predictions on time scales of days to decades. Given the high cost and logistical barriers to collecting these measurements, it is crucial to assess which observations are most essential and to determine where resources should be invested for maximum benefit. In this work,

\footnotetext{
Supplemental information related to this paper is available at the Journals Online website: https://doi.org/10.1175/JCLI-D-190179.s1.
}

\footnotetext{
Corresponding author: Mitch Bushuk, mitchell.bushuk@noaa gov
}

we consider this question from the perspective of seasonal sea ice predictions in the Barents Sea.

The sea ice cover in the Barents Sea is a dominant contributor to winter Arctic sea ice variability and trends (Cavalieri and Parkinson 2012) and influences local economic activity such as fisheries, shipping, and natural resource industries (Jung et al. 2016). These factors have motivated a need for accurate seasonal sea ice predictions in this region. A number of recent studies, using both statistical methods (Schlichtholz 2011; Onarheim et al. 2015) and fully coupled dynamical prediction systems (Krikken et al. 2016; Bushuk et al. 2017), have demonstrated that detrended Barents sea ice extent (SIE) anomalies can be skillfully predicted up to nine months in advance. Additionally, idealized prediction studies using a "perfect model" approach estimate that Barents sea ice is potentially predictable at 
lead times of 16-36 months (Koenigk and Mikolajewicz 2009; Day et al. 2014; Bushuk et al. 2019). These studies suggest that future skill improvements are achievable; however, they may overestimate potential skill due to overly persistent Barents SIE anomalies (Kumar et al. 2014; Blanchard-Wrigglesworth and Bushuk 2019). Closing this prediction skill gap requires a detailed understanding of the physical mechanisms providing predictability in the Barents Sea, and the ability to observe, assimilate, and simulate the salient aspects of these mechanisms.

Barents sea ice variability is driven by a multitude of related factors, including anomalies in oceanic volume and heat transport through the Barents Sea Opening (BSO; Smedsrud et al. 2010; Årthun et al. 2012; Smedsrud et al. 2013; Zhang 2015; Li et al. 2017), thermodynamic and dynamic influences of atmospheric forcing from the North Atlantic Oscillation (Deser et al. 2000; Vinje 2001; Deser and Teng 2008), local persistence of sea surface temperature (SST) anomalies (Blanchard-Wrigglesworth et al. 2011; Day et al. 2014; Bushuk et al. 2015; Bushuk and Giannakis 2015; Ordoñez et al. 2018), variability in wind-driven ice export from the central Arctic (Kwok et al. 2005; Kwok 2009), and local wind and surface heat flux (SHF) anomalies (Sorteberg and Kvingedal 2006; Schlichtholz and Houssais 2011). It has been long understood that the temperature of inflowing Atlantic water through the BSO provides an important control on the Barents winter sea ice edge (see Fig. 59 of Helland-Hansen and Nansen 1909). Recent studies have utilized this fact to make skillful retrospective predictions of Barents SIE, attributing their skill to the persistence of Barents Sea ocean heat content $(\mathrm{OHC})$ anomalies on seasonal time scales (Schlichtholz 2011; Onarheim et al. 2015; Bushuk et al. 2017). Schlichtholz (2011) found that a linear regression model based on summer (June-September) subsurface ocean temperature anomalies at the BSO could skillfully predict detrended sea ice area (SIA) anomalies the following winter (December-March). Using a statistical model based on winter-centered annual mean (July-June) observed BSO ocean heat transport (OHT) and Barents SIA, Onarheim et al. (2015) demonstrated skillful predictions, relative to a linear trend forecast, of the following year's SIA. Bushuk et al. (2017) reported detrended winter Barents SIE prediction skill at lead times of 5-9 months in a dynamical prediction system based on a fully coupled general circulation model (GCM), and attributed this skill to subsurface ocean temperature initial conditions (ICs) and storage of these OHC anomalies below the mixed layer. Both Schlichtholz (2011) and Bushuk et al. (2017) highlighted the fall/winter reemergence of SST anomalies originating the previous spring as a crucial mechanism influencing Barents sea ice predictability.

A question that remains unclear from these studies is the relative role of lateral OHT versus SHF anomalies in driving Barents $\mathrm{OHC}$ variability, and, by extension, the relative importance of subsurface versus surface observations for predictions of Barents sea ice. This work provides insight into this question by directly quantifying the value of different classes of oceanic and atmospheric observations in terms of their influence on seasonal prediction skill for sea ice. We do this by performing a hierarchy of observing system experiments (OSEs) with a coupled global data assimilation system, in which certain observation types are systematically excluded during the assimilation procedure. Initializing retrospective predictions from these OSEs allows for a direct assessment of the influence of various observation types on seasonal prediction skill. This study is the first time that an OSE methodology, which is commonly used in the weather and seasonal forecasting community (e.g., Bouttier and Kelly 2001; Lord et al. 2004), has been applied to the problem of sea ice prediction. This approach reveals the key physical mechanisms underlying Barents sea ice predictability and provides guidance for the development of next-generation seasonal prediction systems and future observing networks.

The plan of this paper is as follows. Section 2 presents the dynamical seasonal prediction system used in this study, the observational datasets used for data assimilation, the experimental design of the OSEs, and our methods for prediction skill assessment. In section 3, we first assess the fidelity of ocean and sea ice state estimates across the OSE assimilation runs in terms of their climatology, trends, and interannual variability. Next, we evaluate the Barents SIE skill of retrospective seasonal predictions initialized from the OSE runs. Finally, we consider the relative contributions of surface and subsurface oceanic data and examine the physical mechanisms contributing to Barents sea ice predictability. Conclusions are presented in section 4.

\section{Methods}

\section{a. The GFDL seasonal prediction system}

This study is based on GCM experiments performed with the Geophysical Fluid Dynamics Laboratory (GFDL) Coupled Model version 2.1 (CM2.1; Delworth et al. 2006), which has nominal horizontal resolutions of $1^{\circ}$ latitude $\times 1^{\circ}$ longitude in the ocean and sea ice components and $2^{\circ}$ latitude $\times 2.5^{\circ}$ longitude in the atmosphere and land components. The CM2.1 model forms the basis for one of the GFDL's dynamical 
seasonal prediction systems, which contributes quasioperational seasonal forecasts to the North American Multi-Model Ensemble (NMME; Kirtman et al. 2014). These seasonal predictions are initialized using the GFDL's Ensemble Coupled Data Assimilation System (ECDA; Zhang et al. 2007; Zhang and Rosati 2010), which is based on the CM2.1 model and described in the following subsection. Note that earlier studies on regional sea ice predictions at GFDL have used the Forecast-oriented Low Ocean Resolution model (FLOR; Vecchi et al. 2014; Bushuk et al. 2017), which contributes seasonal forecasts to the NMME initialized with ocean and sea ice ICs from ECDA. We use CM2.1 for this study because 1) this reduces the potential for initialization shocks in the OSE retrospective predictions, as the ECDA system is based on this model; 2) CM2.1 has significantly reduced computational cost relative to FLOR (by a factor of roughly 20); and 3) CM2.1 has similar seasonal prediction skill to FLOR for Barents SIE.

The sea ice component of CM2.1 is the sea ice simulator version 1 (SIS1; Delworth et al. 2006). SIS1 is a dynamic-thermodynamic sea ice model, which uses a modified Semtner three-layer thermodynamic scheme with two ice layers and one snow layer (Winton 2000), a subgrid-scale ice-thickness distribution with five thickness categories (Bitz et al. 2001), and an elastic-viscousplastic rheology to compute internal ice stresses (Hunke and Dukowicz 1997). The ocean component of CM2.1 is the Modular Ocean Model version 4 (MOM4; Griffies 2012), which employs a rescaled geopotential height vertical coordinate ( $z^{*}$; Griffies et al. 2011). CM2.1 uses 50 vertical ocean levels, with layer thicknesses of $10 \mathrm{~m}$ in the upper $230 \mathrm{~m}$ of the ocean. CM2.1's atmospheric component is Atmospheric Model version 2.1 (AM2.1; Delworth et al. 2006), which uses a cubed-sphere finitevolume dynamical core with 24 vertical levels (Lin 2004; Putman and Lin 2007).

\section{b. The data assimilation system}

The ECDA system employs an ensemble adjustment Kalman filter methodology (EAKF; Anderson 2001) with 12 ensemble members. The EAFK is a sequential DA method. In the forecast step, the coupled model ensemble is integrated forward in time, producing a prior distribution of model states. In the analysis step, available observations are assimilated and are used to update the model state vector via flow-dependent covariances, which are computed using the prior distribution. The updated ensemble of model states is referred to as the posterior distribution, and depends on both the observational error and model error covariances. The ECDA system uses a weakly coupled
DA approach, meaning that observations in a given model component are used to update state variables within that component via flow-dependent covariances, but covariances are not computed across different model components. The coupling in this system arises via the use of the coupled model in the forecast step, allowing for updates in a given model component to be communicated to other model components via fluxes of heat, momentum, and mass. We note that recent work by Kimmritz et al. (2018) investigating SIC assimilation in a perfect model framework showed that strongly coupled DA, in which SIC observations are used to update both sea ice and ocean temperature and salinity states, generally outperformed a weakly coupled approach, in which only the sea ice state was directly updated.

The ECDA system assimilates 3D atmospheric temperatures from the NCEP-DOE Atmospheric Model Intercomparison Project (AMIP-II) reanalysis (Kanamitsu et al. 2002), satellite SSTs from the Met Office Hadley Centre's sea ice and SST dataset (HadISST1; Rayner et al. 2003) (prior to 2011) and NOAA's daily Optimum Interpolation SST dataset (OISST; Reynolds et al. 2007) (post 2011), and a variety of subsurface ocean temperature and salinity $(T / S)$ observations. The subsurface ocean observations come from the World Ocean Database (WOD; Levitus et al. 2013), the Global Temperature and Salinity Profile Programme (GTSPP; Sun et al. 2010) and the Argo program (Roemmich et al. 2004). These ocean data comprise a variety of observation types, including profiling floats (PFL), highresolution conductivity-temperature-depth (CTD) data, expendable bathythermographs (XBT), and ocean station data (OSD). The dominant contributions in the Barents Sea come from OSD (low-resolution CTD and bottle data) prior to the early 1990s and from highresolution CTD data (depth increments of less than $2 \mathrm{~m}$ ) after the early 1990s (see Fig. S1 in the online supplemental material; see also Abrahamsen 2014). The ECDA system does not directly assimilate sea ice observations, but the sea ice state is constrained in the weakly coupled assimilation procedure via fluxes from the atmospheric and oceanic model components. Sea ice DA is planned as future work in this system, which was originally developed with a focus on tropical and midlatitude applications.

ECDA uses a spatial localization of covariances in order to restrict spurious correlations between remote spatial locations. The localization weighting function is a fifth-order piecewise polynomial function [Eq. (4.10) of Gaspari and Cohn (1999)], which has a specified halfwidth parameter $c$, is identically zero for distances beyond $2 c$, and qualitatively resembles a Gaussian 
TABLE 1. Summary of OSEs performed in this study. Hindcast period refers to the years over which seasonal retrospective predictions are performed. Note that OSE prediction skill is evaluated over the period of 1997-2016.

\begin{tabular}{lccccc}
\hline \hline Experiment name & Atmospheric 3D temp & SST & CTD & Other subsurface & Hindcast period \\
\hline Control & $\checkmark$ & $\checkmark$ & $\checkmark$ & $\checkmark$ & $1981-2016$ \\
No CTD & $\checkmark$ & $\checkmark$ & $\times$ & $\checkmark$ & $1995-2016$ \\
No subsurface & $\checkmark$ & $\checkmark$ & $\times$ & $\times$ & $1995-2016$ \\
SST only & $\times$ & $\checkmark$ & $\times$ & $\times$ & $1995-2016$ \\
Atmosphere only & $\checkmark$ & $\times$ & $\times$ & $\times$ & $1995-2016$ \\
Uninitialized & $\times$ & $\times$ & $\times$ & $1861-2016$ \\
\hline
\end{tabular}

function. We refer to the half-width parameter $c$ as the localization distance.

In the ocean component, ECDA uses a horizontal localization distance of $1000 \mathrm{~km}$ and a vertical localization of twice the thickness of the nearest ocean model layer. This vertical localization means that a given ocean observation generally influences the nearest ocean layer and \pm 3 layers in the vertical. SST observations are treated identically to ocean $T / S$ profile observations, and therefore influence the upper four ocean layers. The ocean state vector consists of both $T$ and $S$ at all depths, so both $T$ and $S$ are updated given an observation of $T$ or $S$. The observational errors used by ECDA are $0.5^{\circ} \mathrm{C}$ for $T$ and 0.1 psu for $S$. The daily-mean SST data are assimilated with daily frequency and ocean profiles are assimilated whenever available.

In the atmospheric component, 3D reanalysis temperatures that have been regridded to the atmospheric model grid are assimilated. A 500-km localization is used in the horizontal and the vertical localization is confined to the model layer of the observed quantity. The atmospheric state vector consists of temperature and horizontal velocities at all pressure levels. The observational atmospheric temperature error used in ECDA is $1^{\circ} \mathrm{C}$. The atmospheric data are assimilated with 6-hourly frequency.

ECDA employs a full-field initialization approach, which aims to initialize the model close to the observed state. This approach has the advantage of correcting systematic model biases but the disadvantage of introducing greater initialization shock and model drift, since the model will tend to relax to its attractor when run in forecast mode. An alternative approach used in other prediction systems is anomaly initialization (Meehl et al. 2014), in which the observed anomaly is added to the model's climatology. This tends to result in a more balanced initial state with less model drift, but a larger bias. On the seasonal time scale, full-field initialized forecasts have been shown to generally have higher skill than anomaly-initialized forecasts (Smith et al. 2013; Magnusson et al. 2013), whereas anomaly initialization may offer advantages on interannual-todecadal time scales (Smith et al. 2013; Volpi et al. 2017) but the differences are somewhat equivocal (Hazeleger et al. 2013; Polkova et al. 2014). We assess the impact of model drift in forecasts initialized from ECDA in section $3 b$.

\section{c. Observing System Experiments}

To isolate the impact of specific observations on Barents sea ice predictions in the GFDL prediction system, we perform a series of OSEs. In these experiments, certain data sources are systematically excluded during the assimilation procedure. We consider a hierarchy of six OSE assimilation runs in this study, which are summarized in Table 1:1) a "Control" run in which all mentioned data are assimilated; 2) a "No CTD" run in which CTD data are excluded; 3) a "No Subsurface" run in which all subsurface ocean data are excluded; 4) an "SST Only" run in which only SST data are assimilated; 5) an "Atmosphere Only" run in which only

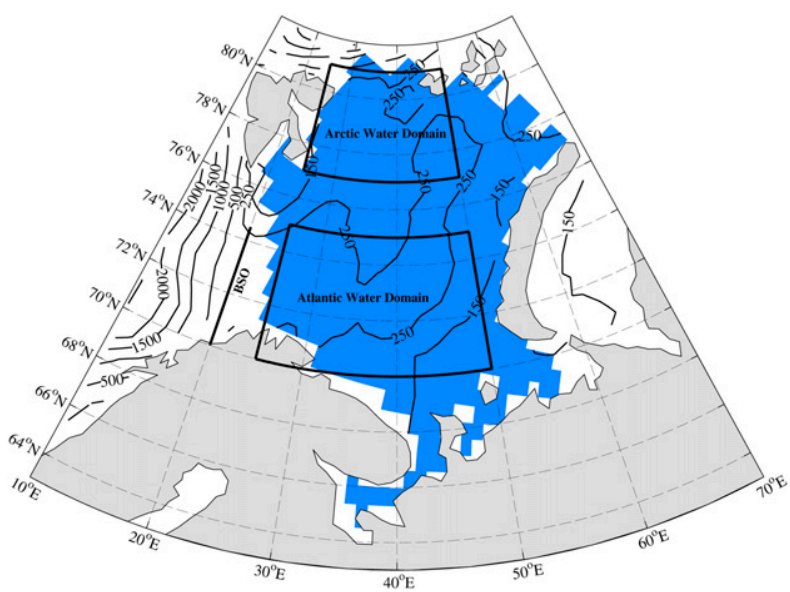

FIG. 1. The Barents Sea domain considered in this study (blue region). The boxed regions enclose the Atlantic water subdomain (defined as $70^{\circ}-75^{\circ} \mathrm{N}, 25^{\circ}-50^{\circ} \mathrm{E}$ ) and the Arctic water subdomain (defined as $77^{\circ}-81^{\circ} \mathrm{N}, 25^{\circ}-50^{\circ} \mathrm{E}$ ). The BSO is marked as the section from $70^{\circ}$ to $74.5^{\circ} \mathrm{N}$ at $20^{\circ} \mathrm{E}$. Ocean bathymetry (m) is plotted in contours. 
JFM hydrography at 100m depth and sea ice edge

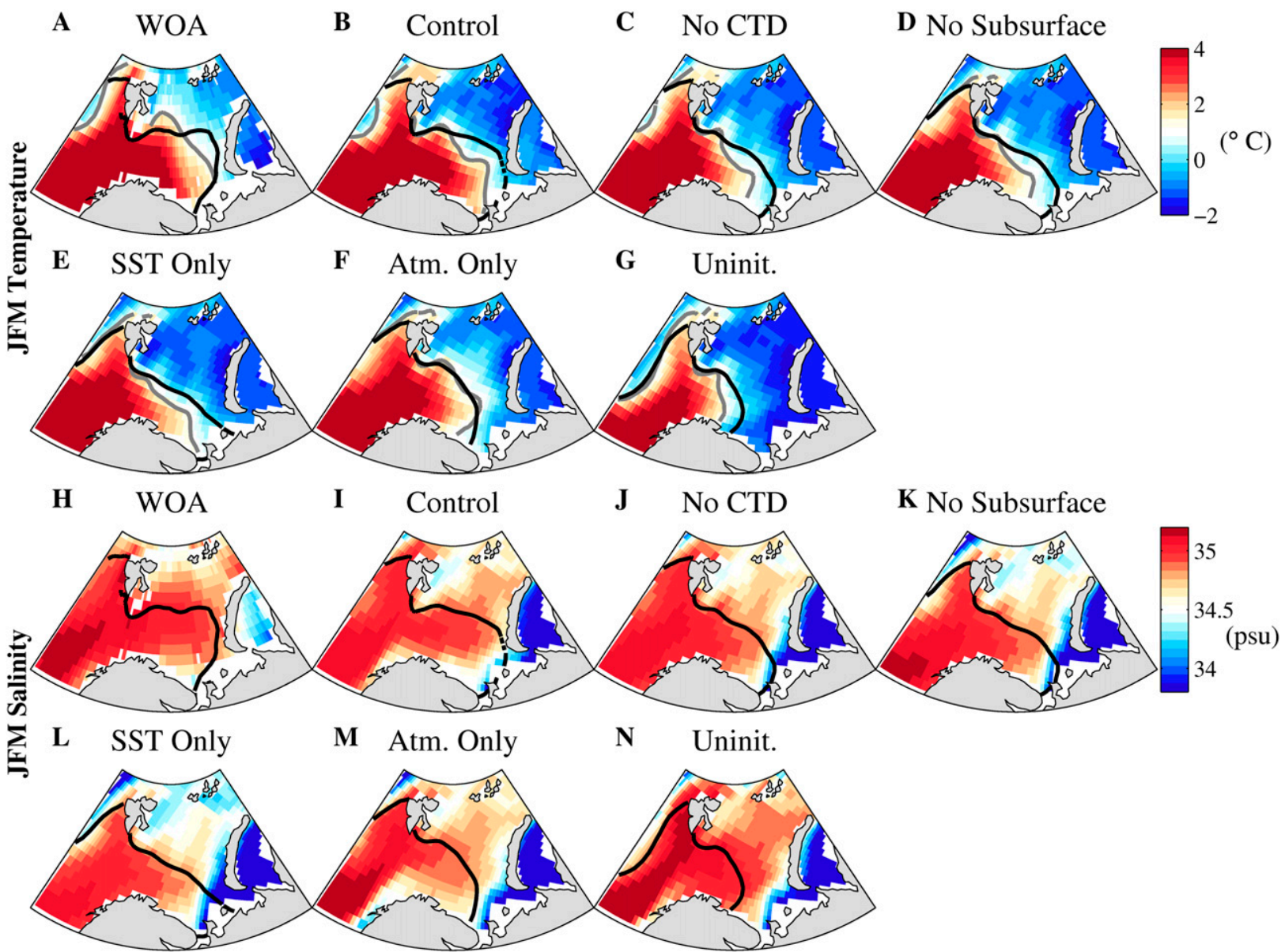

FIG. 2. Barents Sea JFM ocean (a)-(g) temperature and (h)-(n) salinity climatologies at 100-m depth from WOA13 observations and the OSEs. The black contour shows the January-March (JFM) climatological sea ice edge from NSIDC observations and the OSEs. The gray contour indicates the $1^{\circ} \mathrm{C}$ isotherm. These climatologies are computed over the years 1997-2016. The horizontal distribution of temperature and salinity is similar at other depth levels.

atmospheric temperatures are assimilated; and 6) an "Uninitialized" run in which no data are assimilated. Each of these OSE runs is forced with historical timevarying radiative conditions prior to 2005 and representative concentration pathway 4.5 (RCP4.5; Meinshausen et al. 2011) after 2005. The No CTD, No Subsurface, SST Only, and Atmosphere Only runs are initialized from the Control run on 1 January 1995 and run to December 2016. These runs show signs of adjustment over the first two years of integration. We compute all climatologies, trends, and prediction skill metrics over the years 1997 2016 to exclude this initial period of adjustment. The Control run is initialized on 1 January 1960 and the Uninitialized (historical) run is initialized on 1 January 1860. When assessing the ocean and sea ice state estimates for the OSE assimilation runs, we consider the 12-member ensemble mean. For the Uninitialized run, we consider the ensemble mean computed over a 10 -member ensemble of historical simulations. The OSEs of this study extend and build upon an earlier set of experiments performed with the CM2.1 prediction system (Xue et al. 2017).

\section{d. Prediction skill assessment}

The Barents Sea domain considered in this study follows the definition of Bushuk et al. (2017), which has approximate latitude-longitude bounds of $64^{\circ}-81^{\circ} \mathrm{N}$ and $20^{\circ}-60^{\circ} \mathrm{E}$ (see Fig. 1). This domain has a total area of 1.3 million $\mathrm{km}^{2}$ and contains 438 ocean model grid points with nominal horizontal resolution of $55 \mathrm{~km}$. To assess the influence of different observation types on Barents sea ice prediction skill, we perform suites of retrospective seasonal predictions initialized from the Control, No CTD, No Subsurface, SST Only, and Atmosphere Only OSEs. 
For each year from 1995-2016 and each of these OSEs, we run 10-member ensemble forecasts for one year initialized on start dates of 1 January, 1 April, 1 July, and 1 October. This set of retrospective predictions represents a total of 4400 years of model integration. For the Control run, the retrospective forecasts span 1981-2016.

We assess these forecasts against monthly-averaged passive microwave satellite SIC data from the National Snow and Ice Data Center (NSIDC) processed using the NASA Team Algorithm (dataset ID: NSIDC-0051; Cavalieri et al. 1996). The prediction skill of SIE is assessed using the anomaly correlation coefficient (ACC) and the normalized root-mean-square error (NRMSE). The ACC is the Pearson correlation coefficient between the predicted and observed time series, and the NRMSE is the root-mean-square deviation between these time series normalized by the standard deviation of the observed time series. We compute ACC and NRMSE using both full and linearly detrended time series. ACC values close to one and NRMSE values close to zero indicate a high degree of skill, whereas an ACC value of zero and an NRMSE value of one indicate no skill relative to a climatological reference forecast, respectively. We assess the statistical significance of our computed ACC and NRMSE values using a bootstrapped resampling approach, in which the prediction ensemble is repeatedly randomly sampled with replacement in order to produce empirical distribution estimates of the ACC and NRMSE statistics (Efron 1982). For each computed ACC and NRMSE value, we report a $95 \%$ confidence interval based on a bootstrapped sample of 10000 realizations. We also assess our ocean state estimates using the World Ocean Atlas 2013 (WOA13) climatology and 3-monthly temperature and salinity datasets (Locarnini et al. 2013; Zweng et al. 2013).

\section{Results}

\section{a. Ocean and sea ice state estimates in OSEs}

The Barents Sea is characterized by a polar front, which separates relatively warm and saline Atlantic water $\left(T>3^{\circ} \mathrm{C}\right.$ and $\left.S>34.8 \mathrm{psu}\right)$ inflowing through the BSO from relatively cold and fresh Arctic water $(T<$ $0^{\circ} \mathrm{C}$ and $S>34.7 \mathrm{psu}$ ) located in the northern part of the sea (Årthun et al. 2012; Oziel et al. 2016; Lien et al. 2017). As originally noted by Helland-Hansen and Nansen (1909), the position of this front is critical in setting the Barents winter sea ice edge. We find that the presence of a Barents Sea polar front is well reproduced by the OSE assimilation experiments (see Fig. 2). However, the position of this front, and the corresponding sea ice edge, is shifted along an axis oriented in the northeast direction. As the polar front shifts across these experiments, the relative proportion

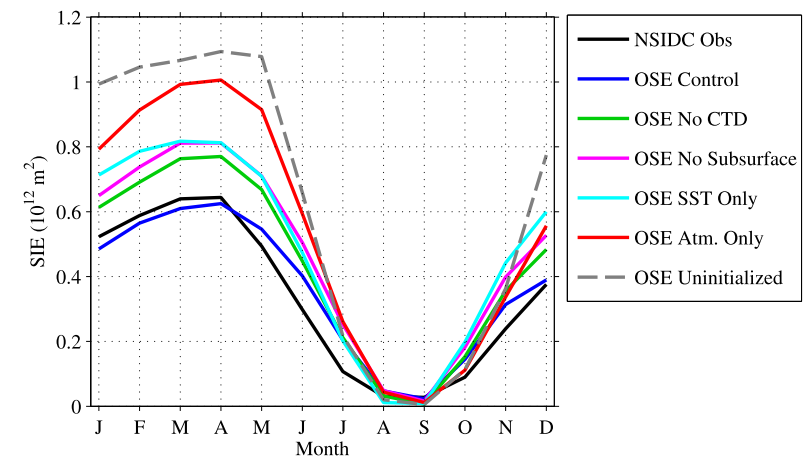

FIG. 3. Barents SIE climatologies computed from the OSE runs. Climatologies are computed over 1997-2016 from NSIDC observations (black), the Control run (blue), the No CTD run (green), the No Subsurface run (magenta), the SST Only run (cyan), the Atmosphere Only run (red), and the Uninitialized run (dashed gray).

of Atlantic and Arctic water masses in the Barents Sea changes. Ahead, we consider ocean profiles computed over "Atlantic water" (defined as $70^{\circ}-75^{\circ} \mathrm{N}$ and $25^{\circ}-50^{\circ} \mathrm{E}$ ) and "Arctic water" (defined as $77^{\circ}-$ $81^{\circ} \mathrm{N}$ and $25^{\circ}-50^{\circ} \mathrm{E}$ ) subdomains of the Barents Sea (see Fig. 1).

We begin by evaluating the fidelity of ocean and sea ice state estimates in the OSE assimilation experiments in terms of their climatology (Figs. 3 and 4). The freerunning CM2.1 model (the Uninitialized run) has a polar front located too far to the southwest (Fig. 2g) and has climatological biases in the Barents Sea characterized by overly extensive sea ice (Fig. 3, dashed gray curve) and ocean temperatures that are too cold at all depths throughout the year (Figs. 4a,b,e,f). The Arctic water subdomain is too saline, particularly below 100-m depth (Figs. 4d,h), and the Atlantic water subdomain has a fresh bias in the upper $100 \mathrm{~m}$ (Figs. 4c,g).

We find that the temperature and SIE biases are notably improved with the inclusion of SST data in the assimilation procedure (see the SST Only run in Figs. 3 and 4 , cyan curve), whereas the water column has been freshened relative to the free-running model (Figs. 4c,d,g,h). These temperature and sea ice improvements primarily result from warmer temperatures in the Atlantic water subdomain (Figs. 4a,e), whereas the salinity degradation is largest in the Arctic water subdomain (Figs. 4d,h). This freshening effect is possibly associated with reduced sea ice formation and a corresponding reduction in brine rejection, as well as the lack of a surface or subsurface salinity constraint in the SST Only run. We find a second notable improvement in the ocean and sea ice state estimates due to the inclusion of subsurface ocean data (the Control run). The Control 
Atlantic Water Domain
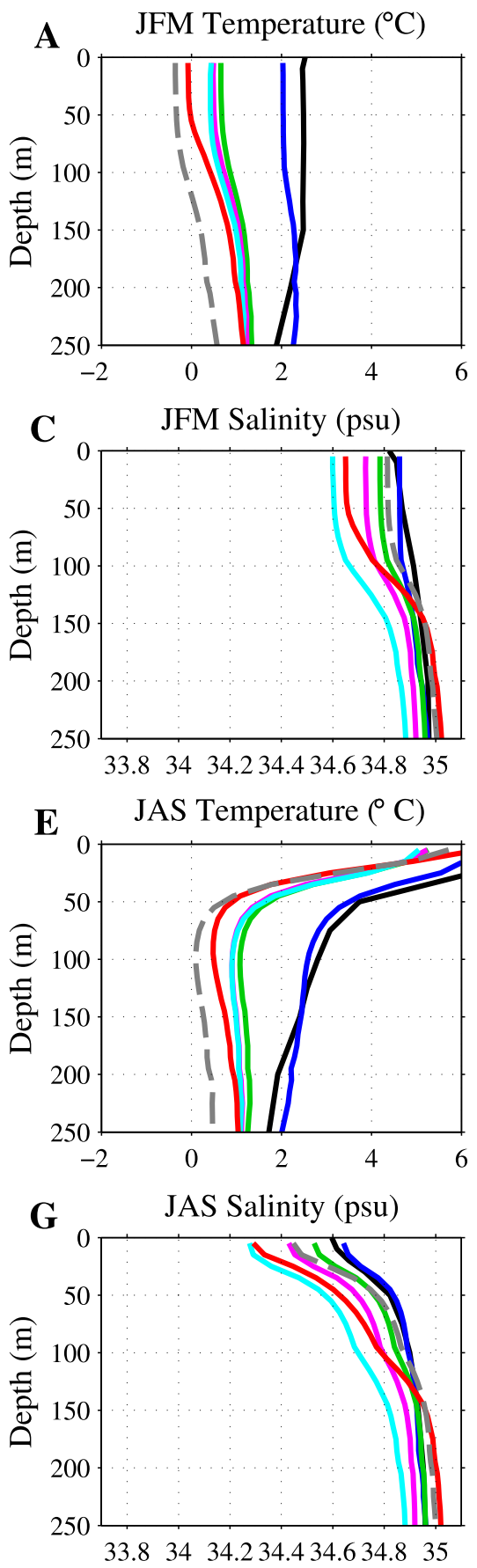

\section{Arctic Water Domain}

B
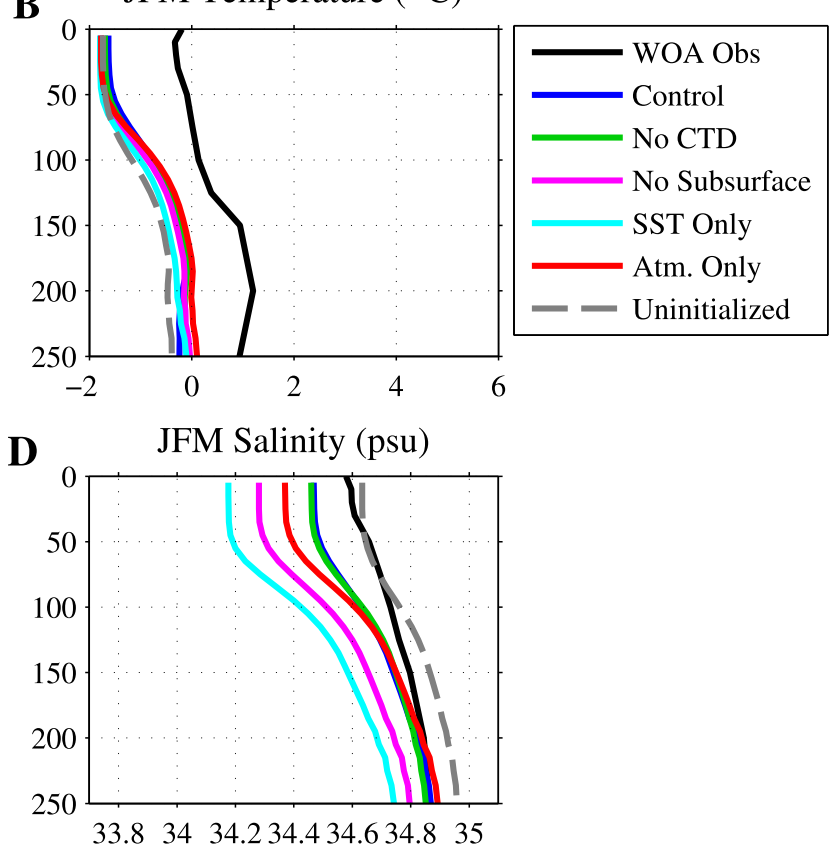

$\mathbf{F}$

JAS Temperature $\left({ }^{\circ} \mathrm{C}\right)$

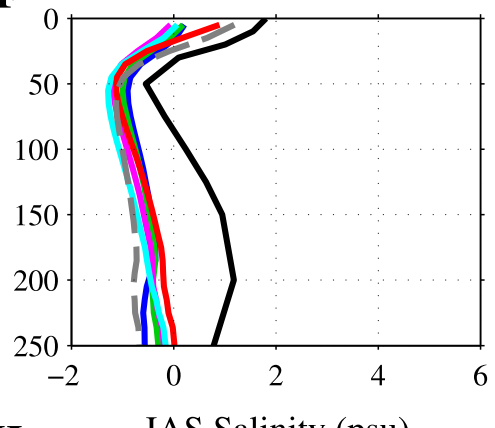

$\mathbf{H}$

JAS Salinity (psu)

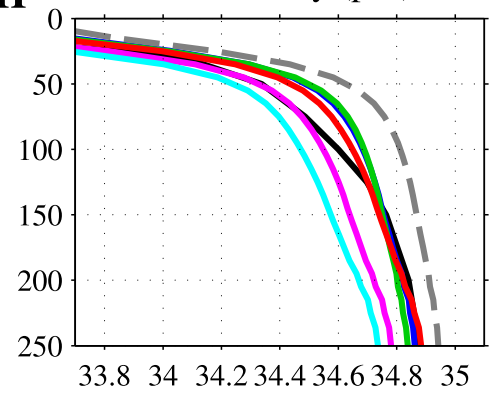

FIG. 4. Temperature and salinity profiles for JFM and JAS computed over 1997-2016 from World Ocean Atlas 2013 (WOA13) observations (black), the Control run (blue), the No CTD run (green), the No Subsurface run (magenta), the SST Only run (cyan), Atmosphere Only run (red), and the Uninitialized run (dashed gray). These profiles are computed over (a),(c),(e),(g) an Atlantic water subdomain of the Barents Sea $\left(70^{\circ}-75^{\circ} \mathrm{N}, 25^{\circ}-50^{\circ} \mathrm{E}\right)$ and (b),(d),(f),(h) an Arctic water subdomain of the Barents Sea $\left(77^{\circ}-81^{\circ} \mathrm{N}, 25^{\circ}-50^{\circ} \mathrm{E}\right)$. 
run captures the observed SIE (Fig. 3, blue curve) and Atlantic subdomain temperature climatologies (Figs. 4a,e) with quite high fidelity, and has an improved salinity climatology relative to the other OSE runs (Figs. 4c,d,g,h). The temperature improvements in this run primarily occur in the Atlantic subdomain, whereas salinity generally shows improvements in both the Atlantic and Arctic subdomains. The improved stratification of the Control run suggests more realistic coupling via vertical mixing between the surface and subsurface ocean layers.

Furthermore, the No CTD run reveals that the critical subsurface ocean contribution comes from CTD data, as the temperature, salinity, and SIE climatologies are each degraded when CTD data are excluded from the assimilation procedure (compare the Control run to the No CTD run in Figs. 3 and 4). The improvements associated with CTD data occur primarily in the Atlantic water subdomain (Figs. 4a,c,e,g, green curves). We additionally find more modest degradations in climatology when the remaining subsurface ocean data are excluded (the No CTD run vs the No Subsurface run). The primary degradation in this case is a freshening of the water column in both winter and summer (Figs. 4c,d,g,h, magenta curves). A similar degradation occurs when atmospheric data are excluded, as the SST Only run has larger salinity biases than the No Subsurface run. The SST Only run resembles the No Subsurface run in terms of sea ice (Fig. 3) and Atlantic water temperatures (Figs. 4a,e), whereas the Atmosphere Only run (red curves) has larger biases in these fields. This suggests that SST generally provides a stronger sea ice and upper ocean temperature constraint than surface atmospheric temperatures. Note that despite assimilating surface ocean temperatures, the SST Only run retains a cold bias in the near-surface ocean. This bias may be related to the vertical localization used in this system, which limits the influence of a given SST observation to the upper $40 \mathrm{~m}$ and may allow for biases in deeper ocean layers to influence the near-surface layers via vertical mixing. Taken together, the results shown in Figs. 3 and 4 suggest that SST and CTD observations provide the most critical data for constraining the ocean and sea ice climatologies in the Barents Sea, and that atmospheric temperatures and other subsurface ocean data provide secondary improvements.

Next, we consider the ability of this assimilation system to capture interannual variations in ocean temperatures and sea ice (Figs. 5a,b). As earlier work has shown that subsurface temperature anomalies stored beneath the summer thermocline provide an important source of predictability for Barents winter SIE (Schlichtholz 2011; Bushuk et al. 2017), we consider
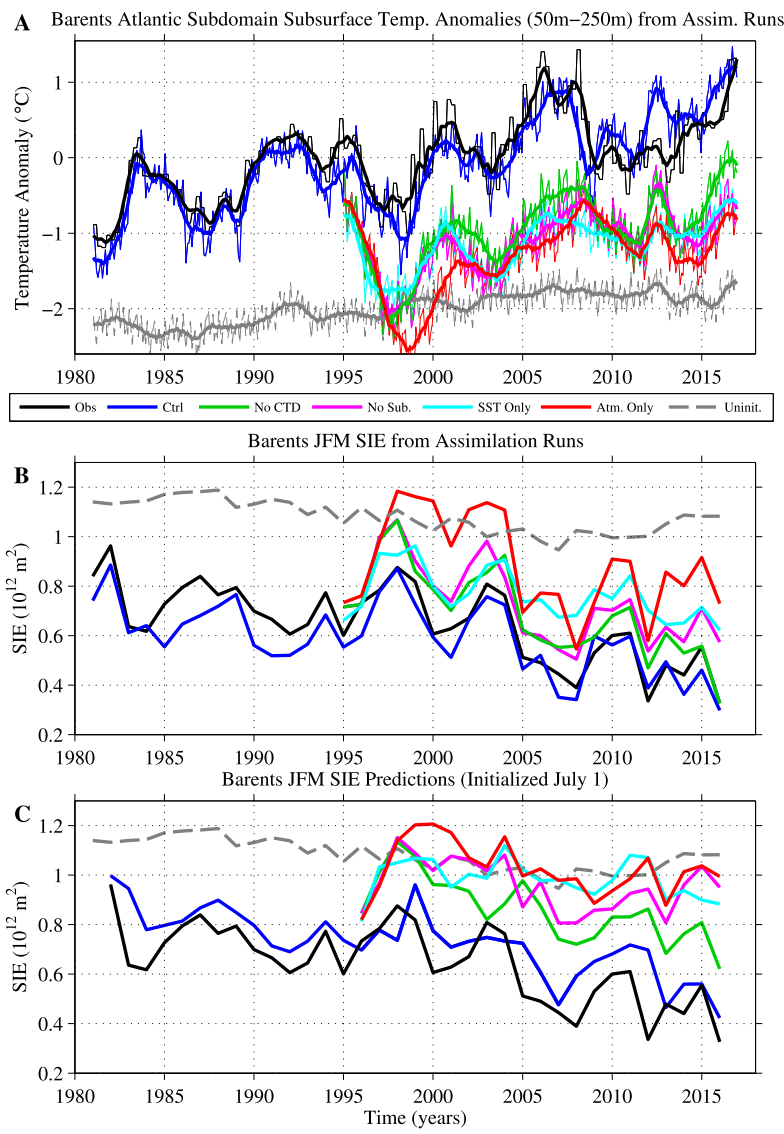

FIG. 5. Ocean and sea ice interannual variability from the OSE runs. (a) Barents Sea Atlantic water subdomain subsurface temperature anomalies (relative to the WOA climatology) averaged between 50 and $250 \mathrm{~m}$ for WOA13 (black) and the OSE runs (colors). Thick lines are 1-yr running means of the monthly data. (b) January-March (JFM) Barents SIE from NSIDC (black) and the OSE assimilation runs. (c) Predictions of JFM Barents SIE initialized from the OSE runs on 1 Jul (lead 6 month). Predictions initialized at other lead times display qualitatively similar behavior.

ocean temperatures averaged between $50-$ and $250-\mathrm{m}$ depth over the Atlantic water subdomain. We find that the Control run captures both the long-term trend and interannual variations in subsurface temperatures with high fidelity (see Fig. 5a). Interestingly, while the No CTD, No Subsurface, SST Only, and Atmosphere Only runs are biased cold relative to the Control, they exhibit similar interannual variability, suggesting that surface data alone are sufficient to constrain the interannual variability of the Barents Sea subsurface heat content. We return to the relative roles of surface versus subsurface data in section 3c. Finally, we find that the Uninitialized model ensemble mean is biased cold, does not capture the observed interannual variability, and underestimates the magnitude of the trend. This clearly illustrates the crucial constraints provided by oceanic and atmospheric data assimilation, as 
incorporation of these data leads to improvements in the system's representation of climatology, trends, and interannual variability.

The observed Barents winter SIE negatively covaries with subsurface temperatures (Schlichtholz 2011; Bushuk et al. 2017) and exhibits analogous behavior across the OSEs. In particular, we find that 1) the Control run matches the observed SIE trend and interannual variability with high fidelity; 2) the No CTD, No Subsurface, SST Only, and Atmosphere Only runs each have positive SIE biases but similar interannual variability to the Control run; and 3) the Uninitialized model ensemble mean fails to capture the observed interannual variability and trend magnitude (Fig. 5b). Overall, we find that the various OSEs generally display monotonic improvements in climatology and interannual variability as additional data are incorporated in the assimilation procedure.

\section{b. Sea ice prediction skill}

We next assess the value of these improved ICs for seasonal predictions of sea ice in the Barents Sea. In order for seasonal predictions to benefit from improved ICs, the prediction model must accurately simulate the dynamical evolution of the initial state, thereby retaining memory of the ICs. We find that, up to lead times of 11 months (the maximum length of these seasonal predictions), the SIE predictions initialized from the different OSEs retain a clear memory of their initial ocean and sea ice states. In particular, predictions initialized from the No CTD, No Subsurface, SST Only, and Atmosphere Only runs have positive SIE biases, whereas the Control run predictions have a substantially reduced bias, associated with their initialization from a state with a warmer subsurface ocean and less extensive sea ice (see Fig. 5c). Analogous to the state estimates in Figs. $5 \mathrm{a}$ and $5 \mathrm{~b}$, we find that the predicted winter SIE from the Control, No CTD, No Subsurface, SST Only, and Atmosphere Only runs also exhibit similar interannual variability. In Fig. 6a, we consider the drift of this system by comparing SIE climatologies from the assimilation runs and lead-6-month predictions. In prediction mode, all OSEs exhibit some degree of drift toward the free-running model climatology; however, the drift is relatively modest in the runs that assimilate subsurface ocean data. For example, the OSE Control retains roughly $80 \%$ of its difference with the Uninitialized run, indicating that the full-field initialization used by this system is a viable prediction approach on the seasonal time scale.

In Fig. 7, we plot the prediction skill of forecasts initialized from the OSEs for target months of JanuaryJune for full (nondetrended) SIE time series. For all

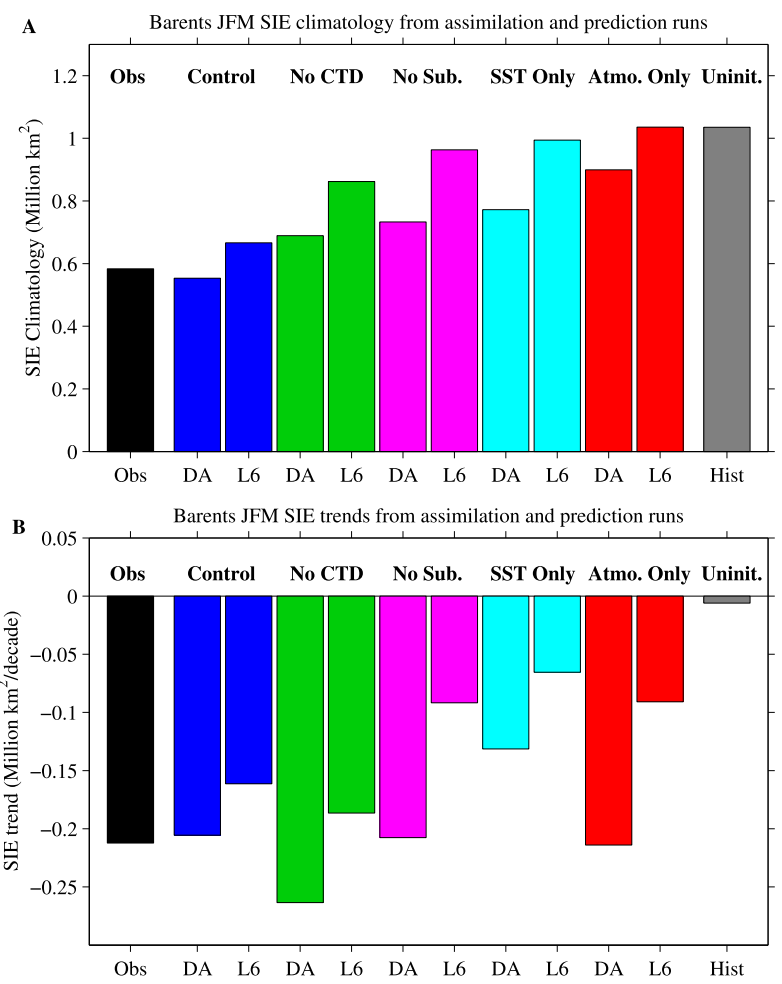

FIG. 6. Barents JFM SIE (a) climatology and (b) trends from observations (black), the Control (blue), No CTD (green), No Subsurface (magenta), SST Only (cyan), Atmosphere Only (red), and Uninitialized (gray) OSE runs. For the OSEs, SIE trends and climatological values are shown for both (left) the assimilation runs (DA) and (right) lead-6-month predictions initialized the previous 1 Jul (L6). Climatologies and trends are computed over years 1997-2016.

considered target months, we find clear improvements in NRMSE as additional data sources are incorporated into the assimilation procedure. In particular, there are monotonic reductions in NRMSE (prediction skill improvements) associated with the incorporation of SST data (cf. the Uninitialized and SST Only predictions in Figs. 7a-f), atmospheric temperature data (cf. the SST Only and No Subsurface predictions), CTD data (cf. the No CTD and Control predictions), and other subsurface ocean data (cf. the No Subsurface and No CTD predictions). The Atmosphere Only predictions are less skillful than the SST Only predictions, again indicating that SST provides a stronger constraint than surface atmospheric temperatures. The Control run NRMSE values are generally significant with respect to a reference climatological prediction, whereas the NRMSE values of the other experiments are not. This demonstrates the large impact of model mean-state biases on forecast skill degradation.

The ACC values, which are unaffected by mean biases, are similar between the Control and No CTD predictions and lower for the No Subsurface, SST Only, and 

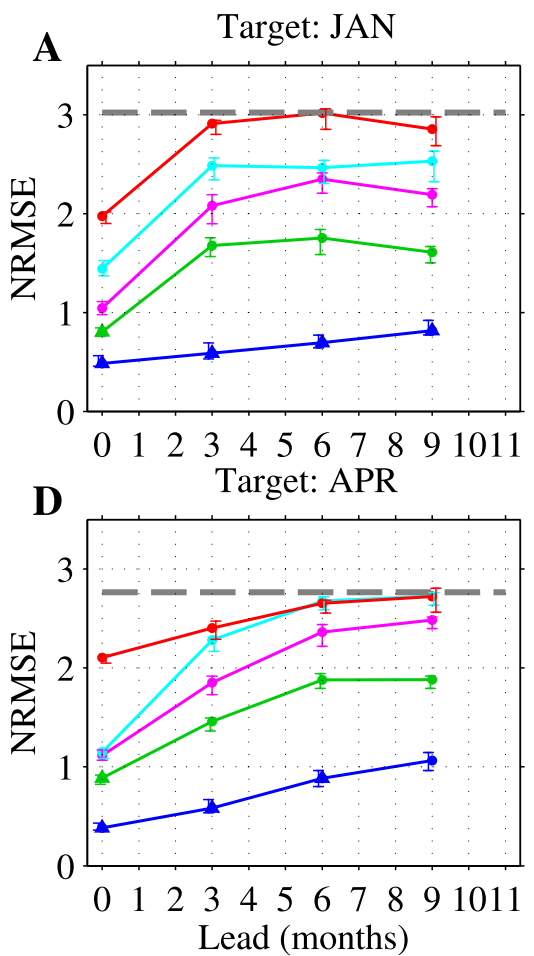

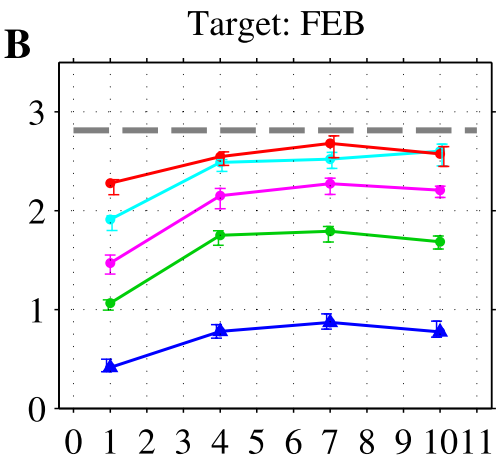

$\mathbf{E}$

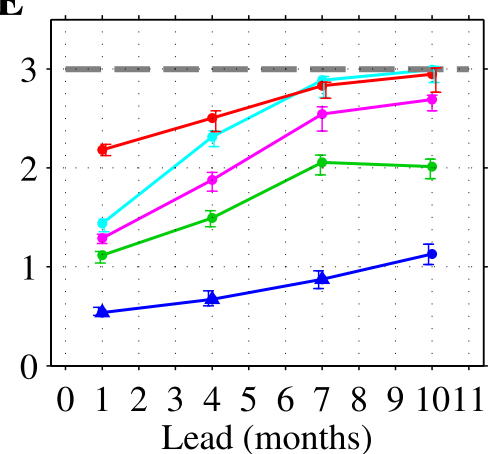

Target: MAR

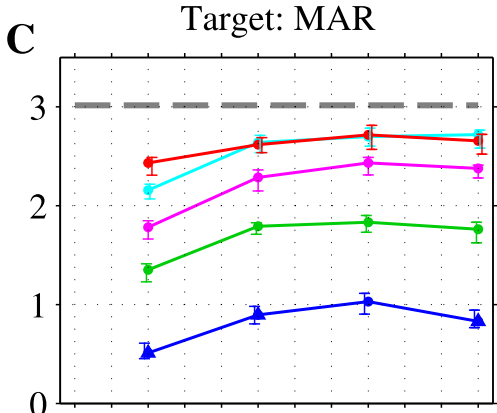

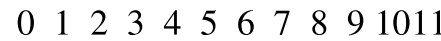
Target: JUN

F

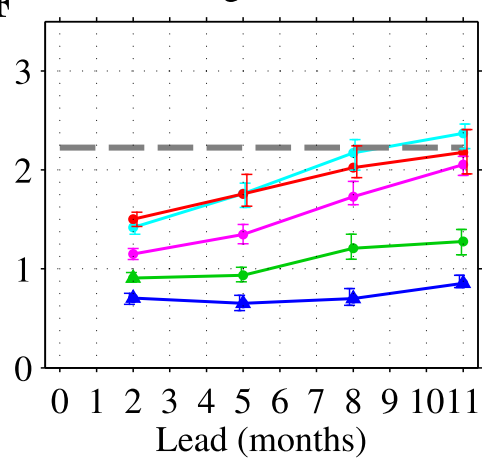

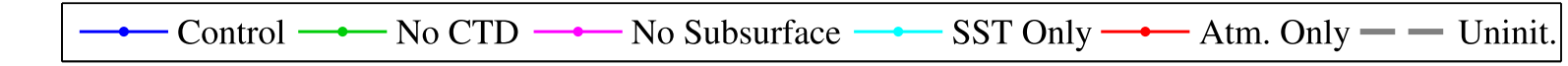
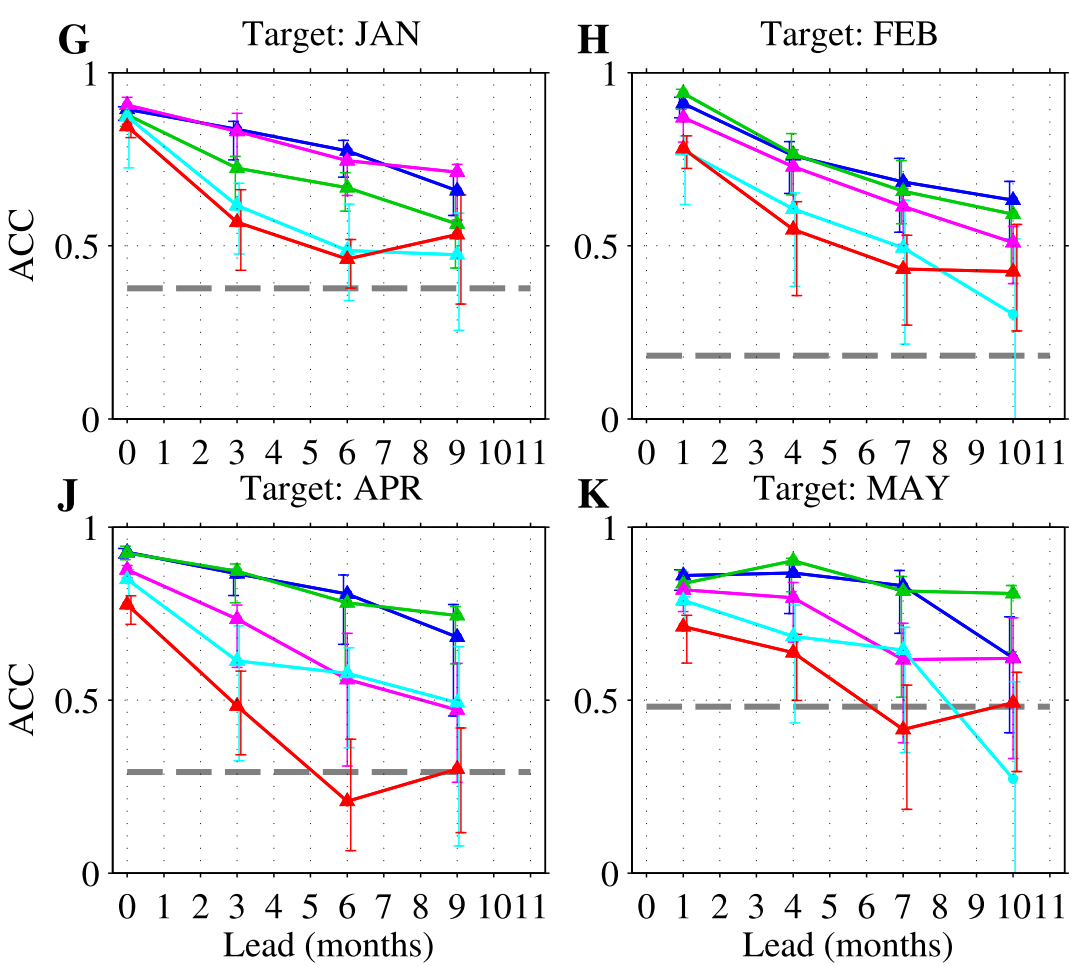

I Target: MAR
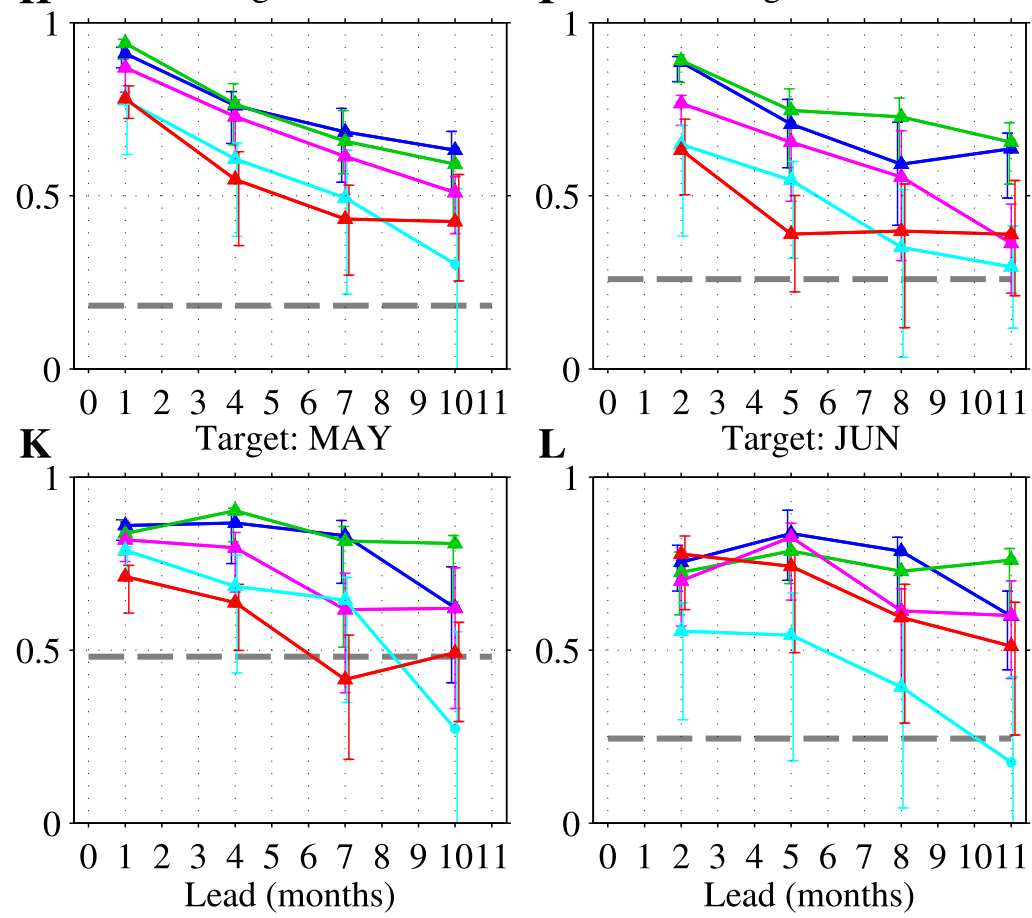

FIG. 7. Sea ice prediction skill. Barents Sea SIE NRMSE and ACC values for target months January-June for predictions initialized from the Control (blue), No CTD (green), No Subsurface (magenta), SST Only (cyan), and Atmosphere Only (red) assimilation runs and the Uninitialized run (dashed gray). Error bars indicate $95 \%$ confidence intervals as estimated by bootstrapping. Triangle markers indicate months in which predictions are statistically more skillful than a climatological reference forecast. The NRMSE and ACC of the climatological reference forecast are 1 and 0, respectively. Prediction skill is computed using years 1997-2016. 
Atmosphere Only predictions (Figs. 7g-1). The Control and No CTD ACC values are statistically higher than both the Uninitialized predictions and a climatological prediction at all lead times. The lower ACC skill in the runs that do not assimilate subsurface ocean data is primarily related to underestimated Barents SIE trends in these predictions (see Fig. 6b). Indeed, the linearly detrended prediction skill plotted in Fig. 8 shows no systematic statistical differences between these experiments, with the exception of the Atmosphere Only run, which has lower detrended ACC and higher detrended NRMSE values. This result indicates that SST data are providing the crucial source of interannual variations in predicted SIE, whereas CTD and other subsurface data are primarily providing corrections of climatological biases and trends, respectively. Note that this set of OSEs (see Table 1) has shown that SST data are sufficient to provide interannual skill, but we have not shown whether SST data are necessary. Answering this question would require a CTD Only experiment, which we plan to explore in future work.

The linear trend in Barents SIE (see Fig. 5b) over the OSE period likely has contributions from both radiative forcing and internal decadal climate variability. While all OSE runs have common radiative forcing, we recover improved predicted trends in the runs that assimilate subsurface ocean data, suggesting that subsurface data provide a useful constraint on decadal ocean variations and/or the forced response of the subsurface ocean. We note that Yeager et al. (2015) found skillful predictions of Atlantic sector SIE trends in decadal prediction experiments initialized based on an ice-ocean simulation forced by surface atmospheric fields (Danabasoglu et al. 2014) but without any direct assimilation of subsurface ocean data. This suggests that the necessary conditions to skillfully predict Barents SIE trends are likely dependent on the model and the initialization technique.

These Barents SIE predictions are skillful on seasonal time scales. Using ACC $=0.5$ as a threshold for practical prediction skill, we find that the Control run is skillful at 3-7 months for detrended SIE, and beyond 11 months for the full time series. For nearly all target months and all OSEs, the skill of the initialized predictions exceeds the uninitialized prediction skill, demonstrating an unambiguous benefit of assimilating observational data. This improved skill is due to improvements in both ocean and sea ice ICs (see Figs. 3-6), the relative importance of which is dependent on lead time. At relatively short lead times ( $0-3$ months) persistence of initial sea ice anomalies are a critical source of prediction skill, whereas at longer lead times (6-9 months) when the Barents Sea is nearly ice free, ocean ICs serve as the key source of predictability.
Predictions of the winter sea ice edge also show clear improvements due to the incorporation of ocean data in the assimilation procedure (Fig. 9), with particularly notable improvements owing to the inclusion of CTD data. While the Control run predictions generally capture the ice edge reasonably well, they fail to predict a feature seen in recent low sea ice years in which the ice edge retreats beyond the northern tip of Novaya Zemlya (see Fig. 9d). This prediction error is possibly related to the significantly higher density of CTD observations in the western portion of the Barents Sea compared with its eastern side. We also note that the predicted Control run ice edge is generally located too far westward, and that the prediction error in Fig. 9d may be related to this bias.

While SST provides the dominant source of winter and spring interannual skill, the relative importance of atmospheric temperatures and SST shifts in the month of June. In June-October, the Atmosphere Only run has higher ACC values (both nondetrended and detrended) than the SST only run (see Figs. S2 and S3 in the supplemental material, and note that this region is essentially ice-free in August and September). The atmospheric constraint is active at all grid points-ice covered and open ocean-whereas SST only provides useful information at ice-free grid points where the SST differs from the freezing point of seawater. Therefore, these summer season skill differences are consistent with the atmospheric data providing a thermodynamic constraint on sea ice thickness in ice-covered regions, which subsequently provides improved ACC skill during the melt season. The NRMSE skill differences between the Atmosphere Only and SST Only runs are more equivocal, suggesting that atmospheric temperatures primarily improve the representation of sea ice thickness interannual variability rather than the climatology.

\section{c. Surface and subsurface oceanic contributions to predictability}

We have demonstrated that both SST and CTD data make substantial positive contributions to seasonal sea ice predictions in the Barents Sea, with SST data providing the key source of interannual variability and CTD data primarily providing a correction to the model's mean-state bias. This finding provides insight into the mechanisms underlying the observed prediction skill, as we have shown that surface data alone are sufficient to constrain interannual $\mathrm{OHC}$ anomalies (Fig. 5a) and to skillfully predict detrended SIE anomalies (Fig. 8). This suggests a possible "top down" mechanism for Barents sea ice predictability as proposed by Schlichtholz (2011), in which anomalous surface heat fluxes provide the key driver of $\mathrm{OHC}$ anomalies and the subsurface ocean acts as a reservoir that stores the memory of this surface 


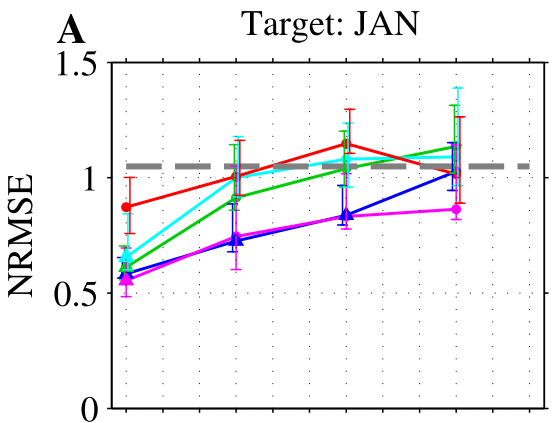

$\begin{array}{lllllllllllll}0 & 1 & 2 & 3 & 4 & 5 & 6 & 7 & 8 & 9 & 1011\end{array}$

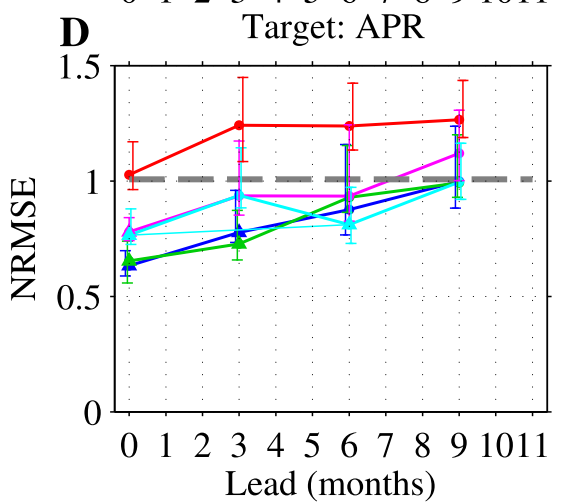

B

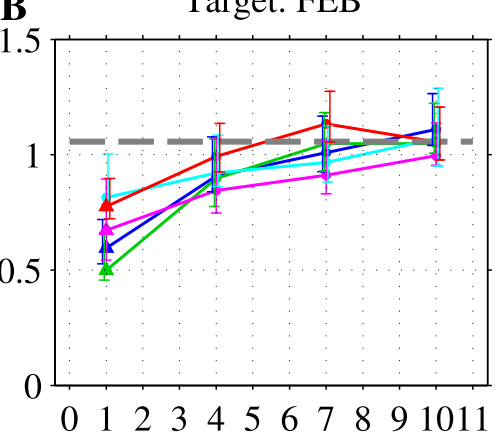

$\mathbf{E}$

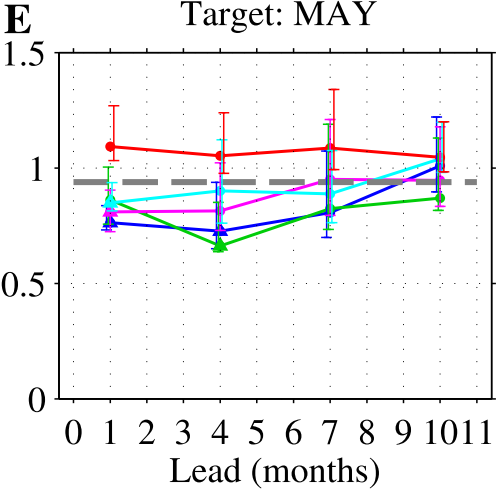

C Target: MAR

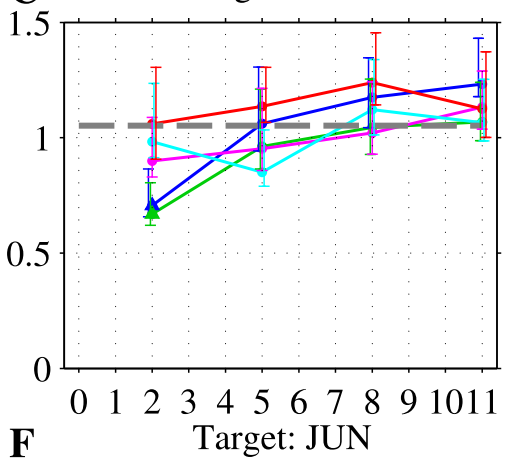

F Target: JUN

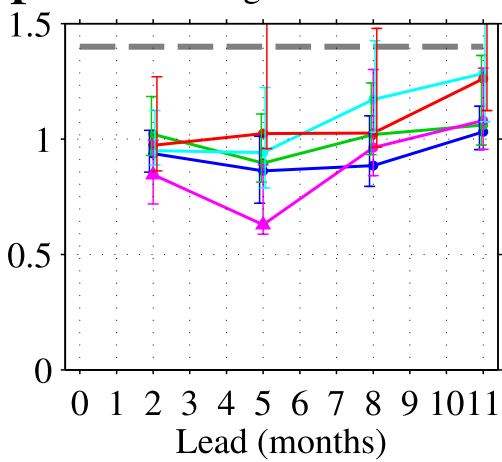

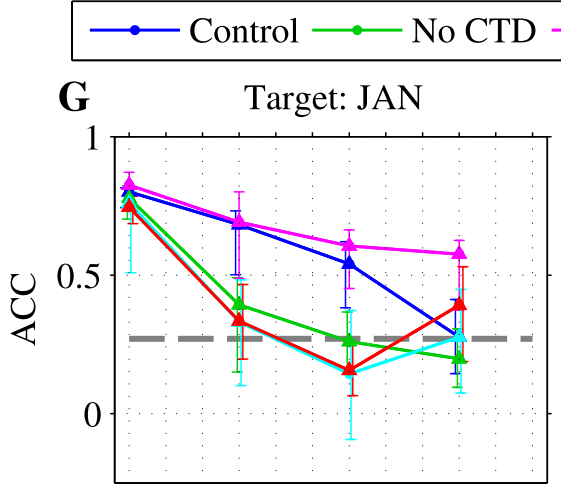
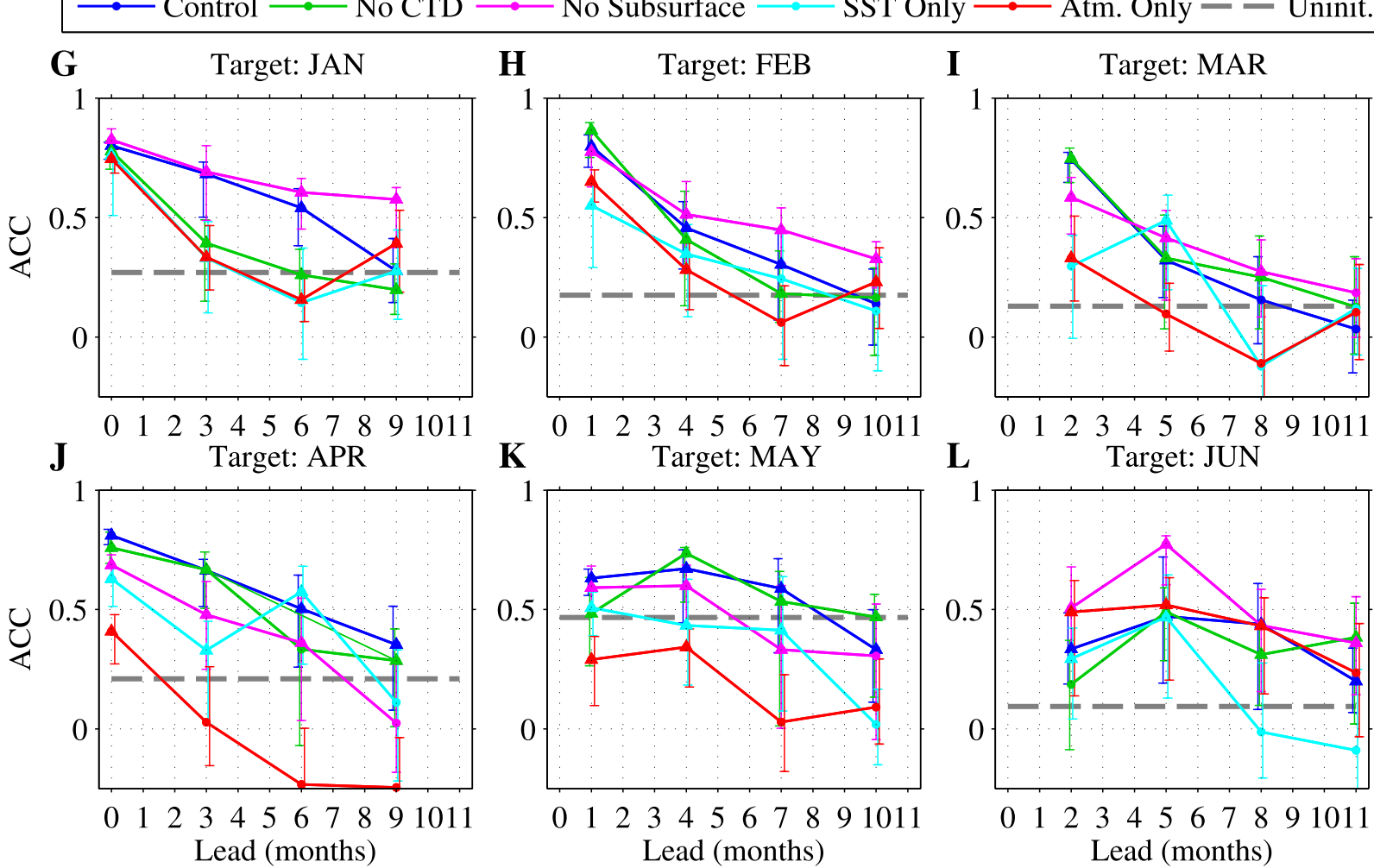

FIG. 8. Detrended Barents SIE NRMSE and ACC values for target months January-June for predictions initialized from the Control (blue), No CTD (green), No Subsurface (magenta), SST Only (cyan), and Atmosphere Only (red) assimilation runs and the Uninitialized run (dashed gray). Error bars indicate $95 \%$ confidence intervals as estimated by bootstrapping. Triangle markers indicate months in which predictions are statistically more skillful than a reference forecast based on the linear trend. The NRMSE and ACC of the linear trend reference forecast are 1 and 0, respectively. Prediction skill is computed using years 1997-2016. 

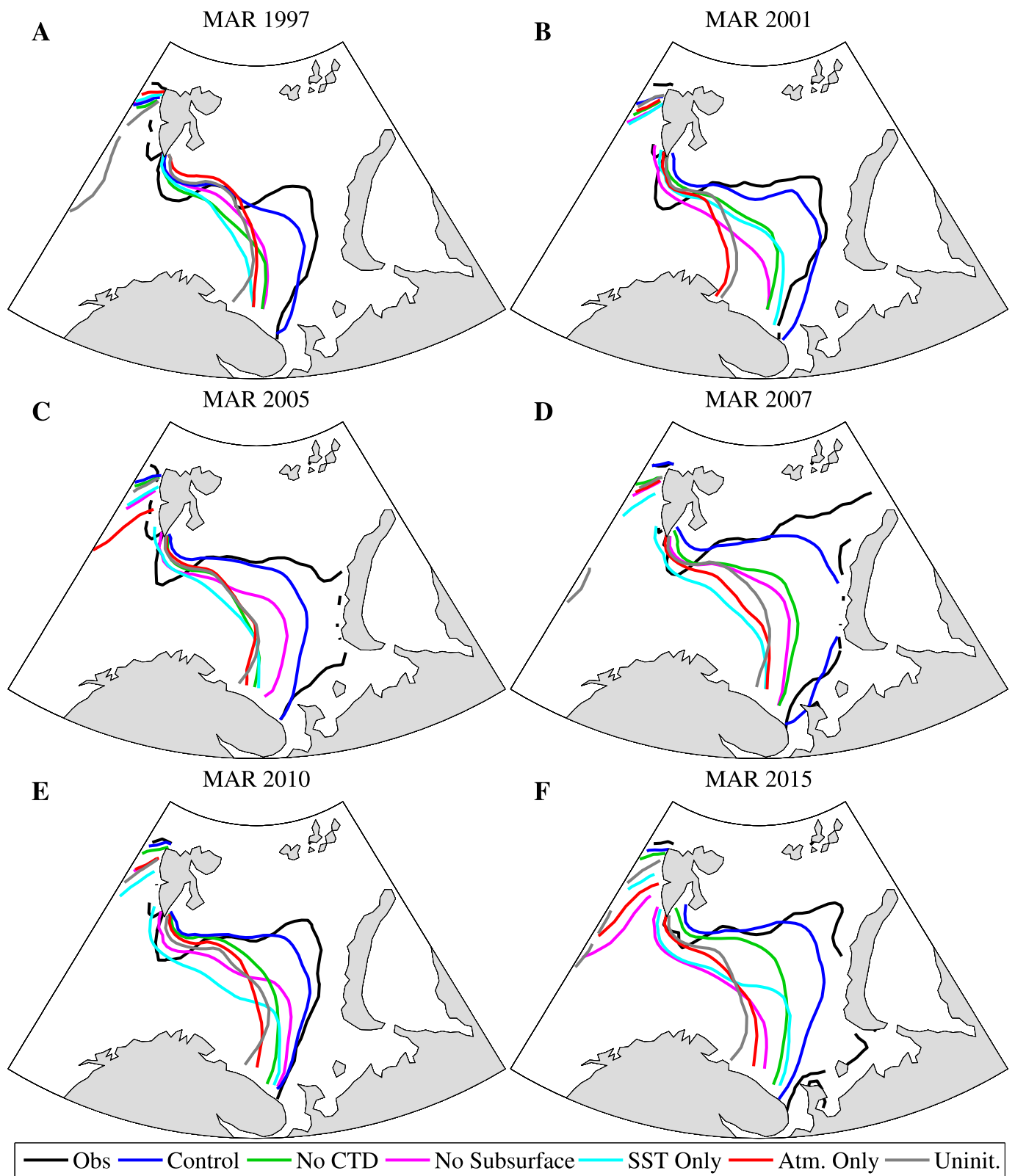

FIG. 9. Sea ice edge predictions. Predictions of the observed Barents Sea March sea ice edge (black) from the Control (blue), No CTD (green), No Subsurface (magenta), SST Only (cyan), Atmosphere Only (red), and Uninitialized (gray) OSE runs. Predicted ice edges for lead time of 8 months are shown for years (a) 1997, (b) 2001, (c) 2005, (d) 2007, (e) 2010, and (f) 2015. The differences in ice-edge position are qualitatively similar for other lead times. These years are chosen to sample different characteristic sea ice states within the OSE period (see Fig. 5b).

forcing. A second plausible mechanism is the lateral advection mechanism of Årthun et al. (2012), who found that winter-centered annual mean Barents OHC variability was primarily driven by variations in BSO Atlantic water volume transport.

To investigate these two viable mechanisms, we consider the net SHF over the Barents Sea, which acts as a driver of $\mathrm{OHC}$ anomalies in the top-down mechanism, and damps $\mathrm{OHC}$ anomalies in the lateral mechanism. We perform this analysis using the OSE Control run, as this run has the best constraint on $\mathrm{OHC}$ and highest seasonal prediction skill. Computing lagged regressions between the detrended SHF (defined as positive downward) and detrended July OHC in the Atlantic water subdomain, we find that positive July OHC anomalies are associated with positive SHF anomalies the previous 


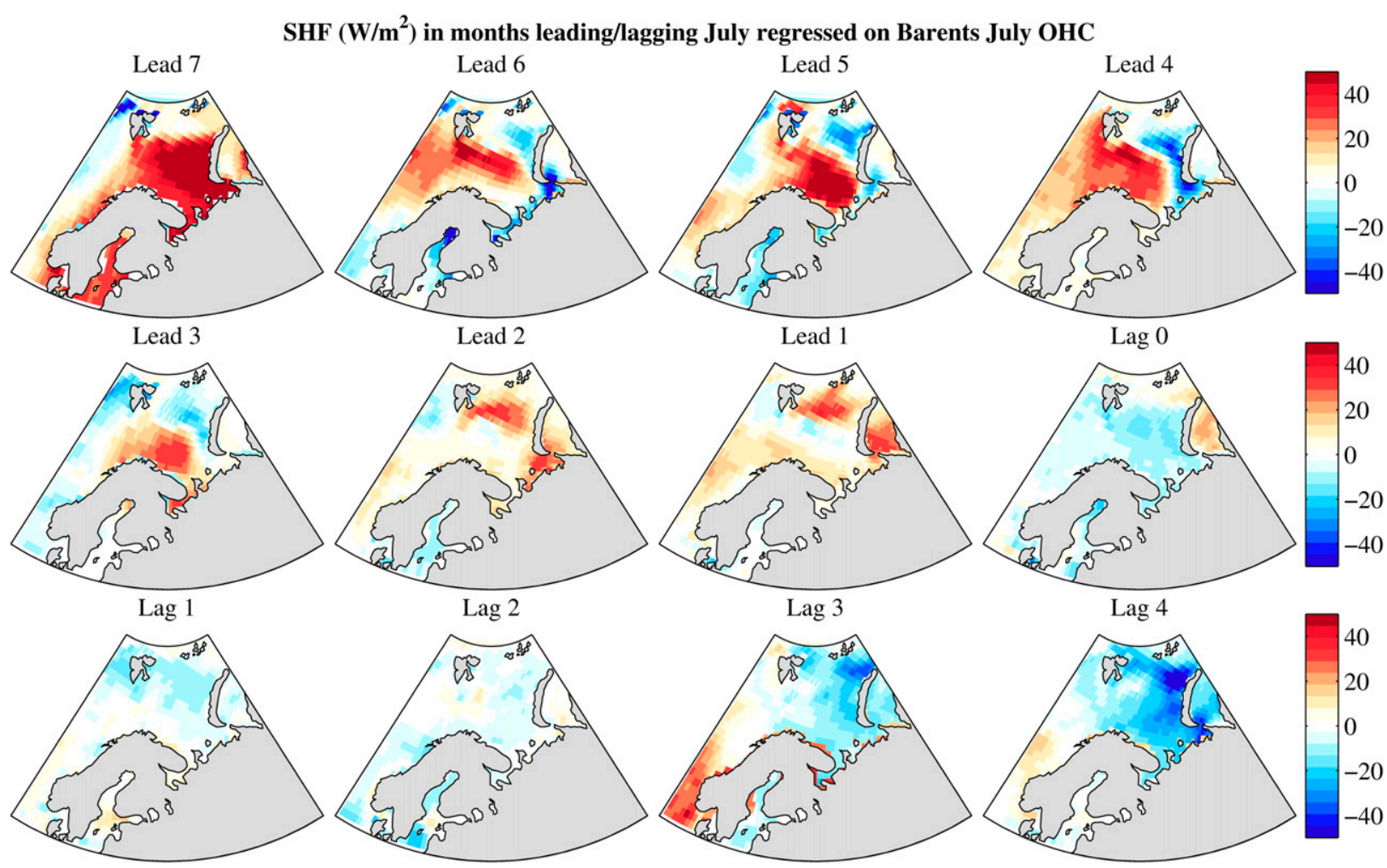

FIG. 10. Regression of the OSE Control run SHF ( $\mathrm{W} \mathrm{m}^{-2}$; defined as positive downward) on Barents July OHC at different leads and lags in months. Positive leads correspond to the SHF preceding July OHC and positive lags correspond to SHF following July OHC.

winter and negative SHF anomalies the following autumn (see Fig. 10), with the dominant contributions coming from sensible and latent heat fluxes. This finding supports the top-down mechanism, suggesting that winter SHF anomalies drive $\mathrm{OHC}$ anomalies, which persist beneath the seasonal thermocline through the summer months and are released to the atmosphere the following autumn as the mixed layer deepens. We note that this finding is insensitive to the choice of July OHC, since Barents $\mathrm{OHC}$ anomalies are persistent on interannual time scales (Fig. 5a).

Surface fluxes produced via a coupled data assimilation procedure that assimilates both atmospheric and oceanic data can potentially be unrealistic, particularly in the presence of systematic model biases. To check the robustness of our findings from the OSE Control run, we repeat the lagged regression analysis by directly using surface fluxes from different atmospheric reanalyses and July OHC from WOA13 observational data. Specifically, we compute lagged regressions using fluxes from both ERA-Interim atmospheric reanalysis (Dee et al. 2011) and NCEP-DOE Reanalysis II (Kanamitsu et al. 2002 ; i.e., the reanalysis product used by ECDA for atmospheric temperature data). We find robust lagged regression patterns across these products, which agree with those identified in the OSE Control run (see Fig. S4 in the supplemental material). In particular, both reanalyses show that positive July OHC anomalies are associated with positive SHF anomalies the previous winter and negative SHF anomalies the following autumn, consistent with the findings from the OSE Control run.

Next, we consider the influence of BSO ocean transport on Barents Sea OHC. We define the BSO section as $70^{\circ}-74.5^{\circ} \mathrm{N}$ and $20^{\circ} \mathrm{E}$ (see Fig. 1), which provides a flux gate between northern mainland Norway and Bear Island, and compute eastward OHT relative to a reference temperature of $0^{\circ} \mathrm{C}$ and eastward ocean volume transport (OVT). Compared to the annual-mean BSO transport estimates of Smedsrud et al. (2010) spanning 1997-2007 [OHT 49.7 TW; OVT $2.0 \mathrm{~Sv} \quad(1 \mathrm{~Sv} \equiv$ $\left.10^{6} \mathrm{~m}^{3} \mathrm{~s}^{-1}\right)$ ], the free-running model (Uninitialized run) has lower heat transport (36.7 TW) and higher volume transport $(2.6 \mathrm{~Sv})$. The Control OSE run has a more realistic OHT (49.5 TW) while retaining a similar volume transport $(2.6 \mathrm{~Sv})$. In Fig. 11, we plot time series of BSO OVT and OHT anomalies from the OSEs. Comparing to the inferred BSO OHT trend of $35 \mathrm{TW}$ per 37 years of Li et al. (2017), the Control run's OHT trend is considerably improved (26 TW per 37 years) relative to the Uninitialized run ( 9 TW per 37 years). We find that 

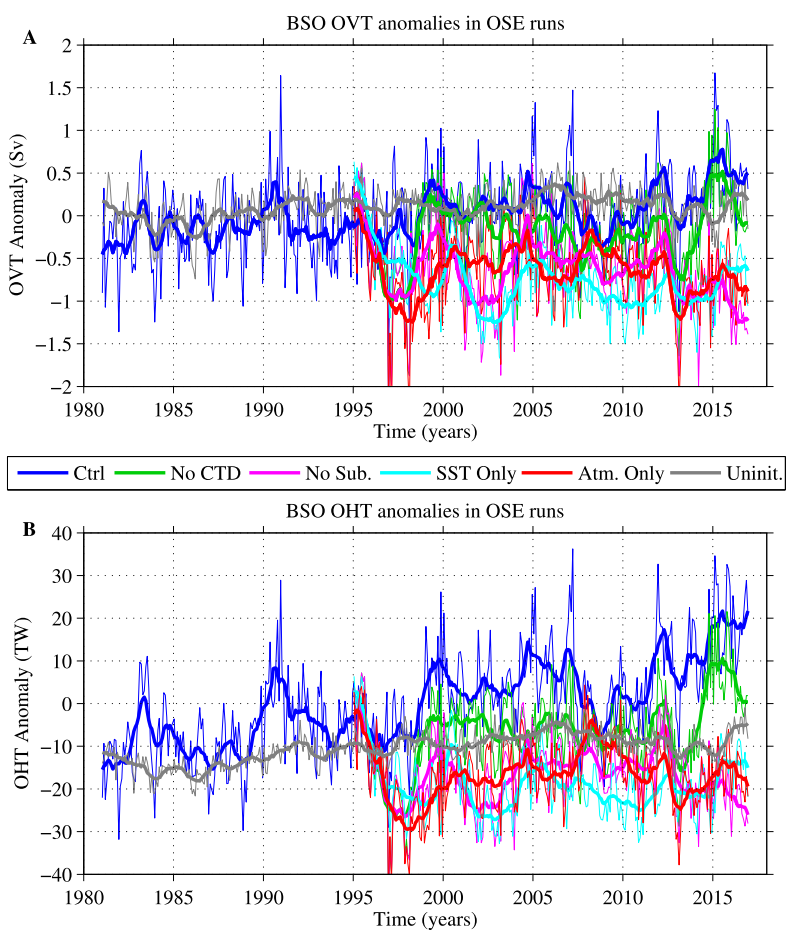

FIG. 11. Time series of (a) OVT (Sv) and (b) OHT (TW) anomalies through the BSO for the Control (blue), No CTD (green), No Subsurface (magenta), SST Only (cyan), Atmosphere Only (red), and Uninitialized (Gray) OSE runs. The anomalies are computed relative to the Control run. The heat transport is computed relative to a reference temperature of $0^{\circ} \mathrm{C}$. Thick lines are 1-yr running means of the monthly data.

the No Subsurface, SST Only, and Atmosphere Only runs have declining volume transports through the BSO, and correspondingly lack the positive OHT trend of the OSE Control experiment. These underestimated OHT trends in the runs that do not assimilate subsurface data are consistent with their underestimated SIE trends (see Fig. 6b).

We now use the OSE Control run to perform a decomposition analysis of BSO OHT. We find that BSO OHT anomalies display a lagged relationship with July $\mathrm{OHC}$, with maximum correlation occurring when $\mathrm{OHT}$ leads by 4 months (March OHT; see Fig. 12a). Decomposing the OHT anomalies into volume transport anomalies (Fig. 12c) and temperature anomalies (Fig. 12b), we find that March temperature anomalies are the dominant source of July $\mathrm{OHC}$ variations with volume transport anomalies playing a much weaker role. These temperature anomalies could either be 1) produced upstream in the North Atlantic and advected into the Barents Sea or 2) produced locally in the Barents Sea via SHF anomalies. In the first case the SHF acts to damp the Barents temperature anomalies, whereas in the second case the $\mathrm{SHF}$ acts to drive the temperature anomalies. Our SHF analysis in Fig. 10 supports case 2, suggesting that winter SHF anomalies are the driver of Barents OHC anomalies. We additionally find that Barents SHF anomalies lead March OHT by $3-4$ months, which is also consistent with winter SHF anomalies being the driver of OHT and OHC anomalies. Overall, these results support the top-down mechanism of Schlichtholz (2011) over the lateral mechanism of Årthun et al. (2012). Note that while we have shown that SHF forcing dominates on seasonal time scales, this does not preclude a crucial role for OVT anomalies on longer time scales (e.g., Zhang 2015; Tietsche et al. 2016).

\section{Conclusions}

We have performed a hierarchy of observing system experiments (OSEs) with a coupled global data assimilation and prediction system in order to quantify the value of various classes of oceanic and atmospheric observations for seasonal forecasts of Barents Sea SIE. This hierarchy consists of six data assimilation experiments, in which oceanic and atmospheric data sources are systematically excluded during the assimilation procedure. We have initialized retrospective seasonal predictions spanning 1995-2016 from these assimilation experiments to directly evaluate the impact of specific observation types on SIE prediction skill. The sea ice and ocean state estimates in the OSEs generally display monotonic improvements in both climatology and interannual variability due to the assimilation of SST, atmospheric temperature, CTD, and other subsurface ocean data, respectively. Particularly notable improvements in climatology are associated with the assimilation of CTD data, whereas SST data are found to provide the crucial source of interannual variability for SIE and subsurface ocean temperatures.

These improved initial conditions have a striking impact on seasonal prediction skill for Barents SIE, demonstrating the unambiguous benefits of assimilating surface and subsurface ocean data. For target months of January-June, we have found monotonic improvements in NRMSE prediction skill associated with the incorporation of SST, atmospheric temperature, CTD, and other subsurface ocean data, respectively. The most significant improvements in NRMSE are specifically associated with CTD data. We have found that ACC skill for SIE is higher in runs that assimilate subsurface ocean data, primarily due to a more realistic representation of sea ice trends in these runs. Using ACC $=0.5$ as a threshold for practical prediction skill, we found that the Control OSE run (which includes all data types considered in this study) is skillful at 3-7 months for detrended SIE, and beyond 11 months for the full time series. The 

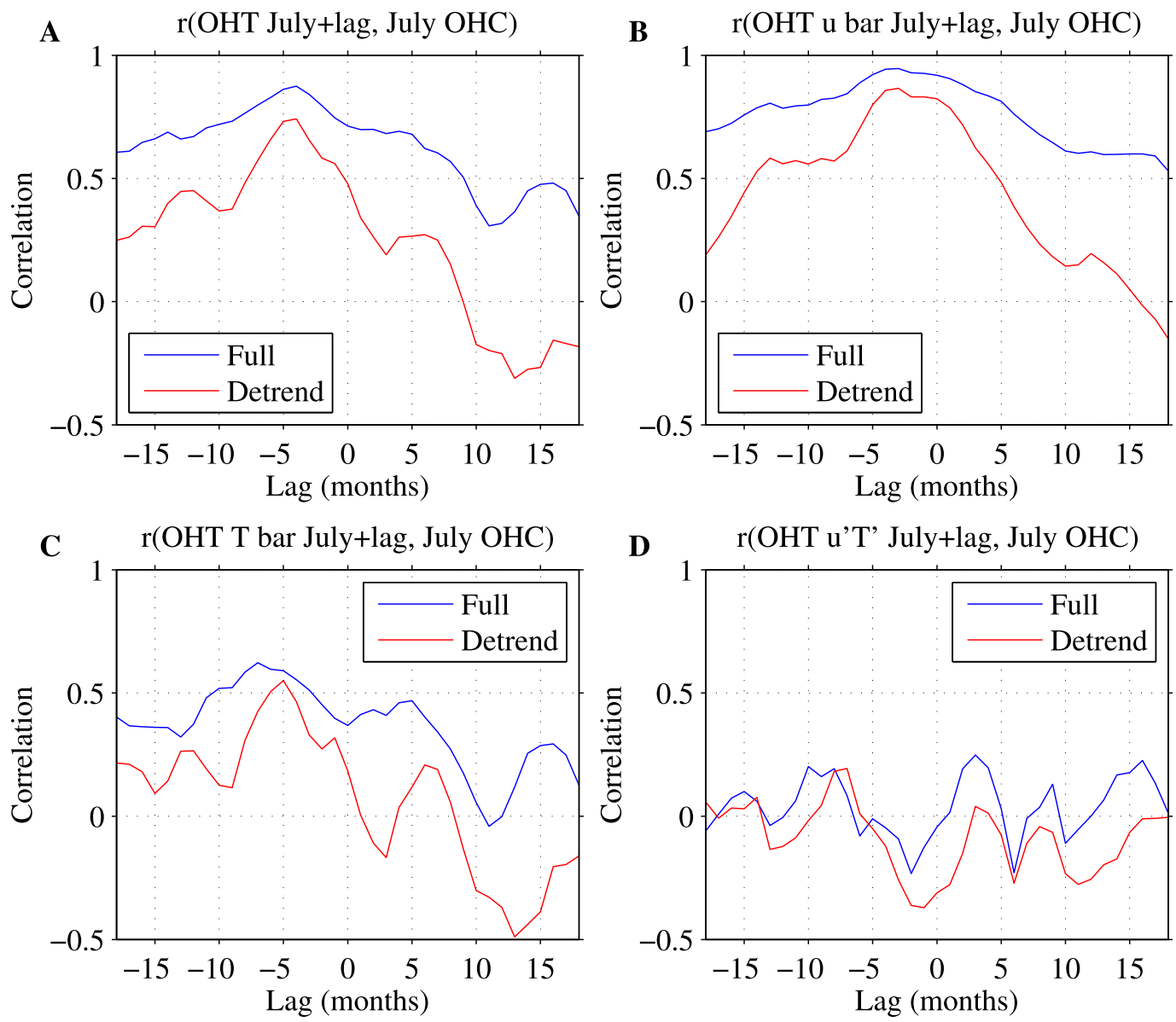

FIG. 12. Lagged correlations between different decompositions of BSO OHT and July OHC from the OSE Control run. Negative lags correspond to OHT leading July OHC and positive lags correspond to OHT lagging July OHC. Shown are (a) full OHT, (b) OHT computed using climatological currents and time-varying temperatures $(\bar{u} T)$, (c) OHT computed using time-varying currents and climatological temperatures $(u \bar{T})$, and (d) OHT anomalies associated with eddy temperature fluxes $\left(u^{\prime} T^{\prime}\right)$. Correlation values using full and detrended time series are plotted in blue and red, respectively.

detrended SIE prediction skill is similar in all runs that assimilate SST, indicating that SST data provide the critical source of interannual variability whereas subsurface ocean data primarily provide improvements in terms of climatology and trends. This finding is supported by analysis of the surface heat budget, which shows that winter SHF anomalies are the driver of Barents Sea OHC variability on seasonal time scales.

The prediction system makes use of the relatively slow time scales of the Barents Sea subsurface ocean to produce skillful sea ice forecasts. Our findings suggest that an unbiased model could achieve similar skill to the Control run using only SST assimilation. However, positive Barents SIE biases are common across CMIP3 (Parkinson et al. 2006) and CMIP5 models (Li et al. 2017), suggesting that subsurface ocean data assimilation would likely be broadly beneficial across other dynamical prediction systems. For summer SIE predictions, we have found that atmospheric temperatures provide a stronger constraint on interannual skill than SST, suggesting a benefit to atmospheric data assimilation over ice-covered regions.

These results highlight the imperative need to sustain existing satellite SST and in situ CTD observing networks, and also suggest that future sea ice prediction improvements could be realized by expanding subsurface ocean observations in the Arctic, potentially via polar Argo floats equipped with ice-avoidance technology (Riser et al. 2018). We advocate that the OSE approach employed in this study is an important paradigm for the future advancement of polar prediction capabilities, as it simultaneously provides an assessment of data assimilation systems, improves understanding of the physical mechanisms impacting prediction skill, and 
provides guidance on the intelligent design of observational networks.

Acknowledgments. We thank Madlen Kimmritz and two anonymous reviewers for constructive feedback that improved the manuscript. We thank Liping Zhang and Feiyu $\mathrm{Lu}$ for comments on a preliminary version of this manuscript. M.B. was supported by NOAA's Climate Program Office, Climate Variability and Predictability Program (Award GC15-504). We thank Fanrong Zeng for providing the OSE Uninitialized simulations and You-Soon Chang for assistance with quality control of WOD data. The NASA team sea ice concentration observations used in this study are available from the National Snow and Ice Data Center website (http://nsidc.org/data/NSIDC-0051/versions/1). The World Ocean Atlas 3-monthly temperature and salinity datasets are available from the NOAA National Centers for Environmental Information website (https:// www.nodc.noaa.gov/OC5/3M_HEAT_CONTENT). The NCEP-DOE II reanalysis data are available from the NOAA Earth System Research Laboratory website (https://www.esrl.noaa.gov/psd/data/gridded/data.ncep. reanalysis 2.html). The ERA-Interim reanalysis data are available from the ECMWF website (https:// www.ecmwf.int/en/forecasts/datasets/archive-datasets/ reanalysis-datasets/era-interim). The OSE assimilation and prediction runs presented in this study are available upon request.

\section{REFERENCES}

Abrahamsen, E., 2014: Sustaining observations in the polar oceans. Philos. Trans. Roy. Soc., 372, 20130337, https://doi.org/ 10.1098/RSTA.2013.0337.

Anderson, J. L., 2001: An ensemble adjustment Kalman filter for data assimilation. Mon. Wea. Rev., 129, 2884-2903, https:// doi.org/10.1175/1520-0493(2001)129<2884:AEAKFF> 2.0. $\mathrm{CO} ; 2$.

Årthun, M., T. Eldevik, L. H. Smedsrud, Ø. Skagseth, and R. Ingvaldsen, 2012: Quantifying the influence of Atlantic heat on Barents sea ice variability and retreat. J. Climate, 25, 47364743, https://doi.org/10.1175/JCLI-D-11-00466.1.

Bitz, C., M. Holland, A. Weaver, and M. Eby, 2001: Simulating the ice-thickness distribution in a coupled climate model J. Geophys. Res., 106, 2441-2463, https://doi.org/10.1029/ 1999JC000113.

Blanchard-Wrigglesworth, E., and M. Bushuk, 2019: Robustness of Arctic sea-ice predictability in GCMs. Climate Dyn., 52, 55555566, https://doi.org/10.1007/s00382-018-4461-3.

— K. C. Armour, C. M. Bitz, and E. DeWeaver, 2011: Persistence and inherent predictability of Arctic sea ice in a GCM ensemble and observations. J. Climate, 24, 231-250, https:// doi.org/10.1175/2010JCLI3775.1.

Bouttier, F., and G. Kelly, 2001: Observing-system experiments in the ECMWF 4D-Var data assimilation system. Quart. J. Roy. Meteor. Soc., 127, 1469-1488, https://doi.org/10.1002/qj.49712757419.
Bushuk, M., and D. Giannakis, 2015: Sea-ice reemergence in a model hierarchy. Geophys. Res. Lett., 42, 5337-5345, https:// doi.org/10.1002/2015GL063972.

,-- , and A. J. Majda, 2015: Arctic sea ice reemergence: The role of large-scale oceanic and atmospheric variability. J. Climate, 28, 5477-5509, https://doi.org/10.1175/JCLI-D-1400354.1 .

, R. Msadek, M. Winton, G. Vecchi, R. Gudgel, A. Rosati, and X. Yang, 2017: Skillful regional prediction of Arctic sea ice on seasonal timescales. Geophys. Res. Lett., 44, 4953-4964, https://doi.org/10.1002/2017GL073155.

,,,,---- X. Yang, A. Rosati, and R. Gudgel, 2019: Regional Arctic sea-ice prediction: Potential versus operational seasonal forecast skill. Climate Dyn., 52, 2721-2743, https://doi.org/10.1007/S00382-018-4288-Y.

Cavalieri, D. J., and C. L. Parkinson, 2012: Arctic sea ice variability and trends, 1979-2010. Cryosphere, 6, 881-889, https://doi.org/ 10.5194/tc-6-881-2012.

$\longrightarrow,-$, P. Gloersen, and H. J. Zwally, 1996 (updated yearly): Sea ice concentrations from Nimbus-7 SMMR and DMSP SSM/I-SSMIS Passive Microwave Data, version 1. NASA DAAC at the National Snow and Ice Data Center, accessed 20 May 2018, https://doi.org/10.5067/8GQ8LZQVL0VL.

Danabasoglu, G., and Coauthors, 2014: North Atlantic simulations in Coordinated Ocean-ice Reference Experiments phase II (CORE-II). Part I: Mean states. Ocean Modell., 73, 76-107, https://doi.org/10.1016/j.ocemod.2013.10.005.

Day, J., S. Tietsche, and E. Hawkins, 2014: Pan-Arctic and regional sea ice predictability: Initialization month dependence. J. Climate, 27, 4371-4390, https://doi.org/10.1175/JCLI-D-1300614.1.

Dee, D. P., and Coauthors, 2011: The ERA-Interim reanalysis: Configuration and performance of the data assimilation system. Quart. J. Roy. Meteor. Soc., 137, 553-597, https://doi.org/ 10.1002/qj.828.

Delworth, T. L., and Coauthors, 2006: GFDL's CM2 global coupled climate models. Part I: Formulation and simulation characteristics. J. Climate, 19, 643-674, https://doi.org/10.1175/ JCLI3629.1.

Deser, C., and H. Teng, 2008: Evolution of Arctic sea ice concentration trends and the role of atmospheric circulation forcing, 1979-2007. Geophys. Res. Lett., 35, L02504, https://doi.org/ 10.1029/2007GL032023.

_ J. E. Walsh, and M. S. Timlin, 2000: Arctic sea ice variability in the context of recent atmospheric circulation trends. J. Climate, 13, 617-633, https://doi.org/10.1175/1520-0442(2000)013<0617: ASIVIT $>2.0 . \mathrm{CO} ; 2$.

Efron, B., 1982: The Jackknife, the Bootstrap, and Other Resampling Plans. SIAM, 92 pp.

Gaspari, G., and S. E. Cohn, 1999: Construction of correlation functions in two and three dimensions. Quart. J. Roy. Meteor. Soc., 125, 723-757, https://doi.org/10.1002/qj.49712555417.

Griffies, S. M., 2012: Elements of the Modular Ocean Model (MOM). GFDL Ocean Group Technical Report. Tech. Rep. No. 7, NOAA/GFDL, 632 pp.

- and Coauthors, 2011: The GFDL CM3 coupled climate model: Characteristics of the ocean and sea ice simulations. J. Climate, 24, 3520-3544, https://doi.org/10.1175/2011JCLI3964.1.

Hazeleger, W., V. Guemas, B. Wouters, S. Corti, I. AndreuBurillo, F. Doblas-Reyes, K. Wyser, and M. Caian, 2013: Multiyear climate predictions using two initialization strategies. Geophys. Res. Lett., 40, 1794-1798, https://doi.org/ $10.1002 / g r l .50355$ 
Helland-Hansen, B., and F. Nansen, 1909: The Norwegian Sea: Its physical oceanography based upon the Norwegian research 1900-1904. Det Mallingske Bogtrykkeri, 402 pp.

Hunke, E., and J. Dukowicz, 1997: An elastic-viscous-plastic model for sea ice dynamics. J. Phys. Oceanogr., 27, 1849-1867, https://doi.org/10.1175/1520-0485(1997)027<1849:AEVPMF> 2.0.CO;2.

Jung, T., and Coauthors, 2016: Advancing polar prediction capabilities on daily to seasonal time scales. Bull. Amer. Meteor. Soc., 97, 1631-1647, https://doi.org/10.1175/BAMS-D-1400246.1.

Kanamitsu, M., W. Ebisuzaki, J. Woollen, S.-K. Yang, J. Hnilo, M. Fiorino, and G. Potter, 2002: NCEP-DOE AMIP-II Reanalysis (R-2). Bull. Amer. Meteor. Soc., 83, 1631-1643, https://doi.org/10.1175/BAMS-83-11-1631.

Kimmritz, M., F. Counillon, C. Bitz, F. Massonnet, I. Bethke, and Y. Gao, 2018: Optimising assimilation of sea ice concentration in an Earth system model with a multicategory sea ice model. Tellus, 70A, 1-23, https://doi.org/10.1080/ 16000870.2018.1435945.

Kirtman, B. P., and Coauthors, 2014: The North American multimodel ensemble: Phase-1 seasonal-to-interannual prediction; phase-2 toward developing intraseasonal prediction. Bull. Amer. Meteor. Soc., 95, 585-601, https://doi.org/10.1175/ BAMS-D-12-00050.1.

Koenigk, T., and U. Mikolajewicz, 2009: Seasonal to interannual climate predictability in mid and high northern latitudes in a global coupled model. Climate Dyn., 32, 783-798, https:// doi.org/10.1007/s00382-008-0419-1.

Krikken, F., M. Schmeits, W. Vlot, V. Guemas, and W. Hazeleger, 2016: Skill improvement of dynamical seasonal Arctic sea ice forecasts. Geophys. Res. Lett., 43, 5124-5132, https://doi.org/ 10.1002/2016GL068462.

Kumar, A., P. Peng, and M. Chen, 2014: Is there a relationship between potential and actual skill? Mon. Wea. Rev., 142, 22202227, https://doi.org/10.1175/MWR-D-13-00287.1.

Kwok, R., 2009: Outflow of Arctic Ocean sea ice into the Greenland and Barents Seas: 1979-2007. J. Climate, 22, 2438-2457, https://doi.org/10.1175/2008JCLI2819.1.

— W. Maslowski, and S. W. Laxon, 2005: On large outflows of Arctic sea ice into the Barents Sea. Geophys. Res. Lett., 32, L22503, https://doi.org/10.1029/2005GL024485.

Levitus, S., and Coauthors, 2013: The World Ocean Database. Data Sci. J., 12, WDS229-WDS234, https://doi.org/10.2481/ DSJ.WDS-041.

Li, D., R. Zhang, and T. R. Knutson, 2017: On the discrepancy between observed and CMIP5 multi-model simulated Barents Sea winter sea ice decline. Nat. Comm., 8, 14991, https:// doi.org/10.1038/ncomms14991.

Lien, V. S., P. Schlichtholz, Ø. Skagseth, and F. B. Vikeb $\varnothing, 2017$ : Wind-driven Atlantic water flow as a direct mode for reduced Barents Sea ice cover. J. Climate, 30, 803-812, https://doi.org/ 10.1175/JCLI-D-16-0025.1.

Lin, S.-J., 2004: A “vertically Lagrangian" finite-volume dynamical core for global models. Mon. Wea. Rev., 132, 2293-2307, https://doi.org/10.1175/1520-0493(2004)132<2293:AVLFDC> 2.0.CO;2.

Locarnini, R. A., and Coauthors, 2013: Temperature. Vol. 1, World Ocean Atlas 2013, NOAA Atlas NESDIS 73, 40 pp.

Lord, S., T. Zapotocny, and J. Jung, 2004: Observing system experiments with NCEP's global forecast system. Third WMO Workshop on the Impact of Various Observing Systems on Numerical Weather Prediction, Alpbach, Austria, WMO, 56-62.
Magnusson, L., M. Alonso-Balmaseda, S. Corti, F. Molteni, and T. Stockdale, 2013: Evaluation of forecast strategies for seasonal and decadal forecasts in presence of systematic model errors. Climate Dyn., 41, 2393-2409, https://doi.org/10.1007/ s00382-012-1599-2.

Meehl, G. A., and Coauthors, 2014: Decadal climate prediction: An update from the trenches. Bull. Amer. Meteor. Soc., 95, 243267, https://doi.org/10.1175/BAMS-D-12-00241.1.

Meinshausen, M., and Coauthors, 2011: The RCP greenhouse gas concentrations and their extensions from 1765 to 2300 . Climatic Change, 109, 213-241, https://doi.org/10.1007/s10584011-0156-z.

Onarheim, I. H., T. Eldevik, M. Årthun, R. B. Ingvaldsen, and L. H. Smedsrud, 2015: Skillful prediction of Barents Sea ice cover. Geophys. Res. Lett., 42, 5364-5371, https://doi.org/ 10.1002/2015GL064359.

Ordoñez, A. C., C. M. Bitz, and E. Blanchard-Wrigglesworth, 2018: Processes controlling Arctic and Antarctic sea ice predictability in the Community Earth System Model. J. Climate, 31, 9771-9786, https://doi.org/10.1175/JCLI-D-18-0348.1.

Oziel, L., J. Sirven, and J.-C. Gascard, 2016: The Barents Sea frontal zones and water masses variability (1980-2011). Ocean Sci., 12, 169-184, https://doi.org/10.5194/os-12-169-2016.

Parkinson, C. L., K. Y. Vinnikov, and D. J. Cavalieri, 2006: Evaluation of the simulation of the annual cycle of Arctic and Antarctic sea ice coverages by 11 major global climate models. J. Geophys. Res., 111, C07012, https://doi.org/10.1029/ $2005 \mathrm{JC} 003408$.

Polkova, I., A. Köhl, and D. Stammer, 2014: Impact of initialization procedures on the predictive skill of a coupled oceanatmosphere model. Climate Dyn., 42, 3151-3169, https:// doi.org/10.1007/s00382-013-1969-4.

Putman, W. M., and S.-J. Lin, 2007: Finite-volume transport on various cubed-sphere grids. J. Comput. Phys., 227, 55-78, https://doi.org/10.1016/j.jcp.2007.07.022.

Rayner, N. A., D. E. Parker, E. B. Horton, C. K. Folland, L. V. Alexander, D. P. Rowell, E. C. Kent, and A. Kaplan, 2003: Global analyses of sea surface temperature, sea ice, and night marine air temperature since the late nineteenth century. J. Geophys. Res., 108, 4407, https://doi.org/10.1029/ 2002JD002670.

Reynolds, R. W., T. M. Smith, C. Liu, D. B. Chelton, K. S. Casey, and M. G. Schlax, 2007: Daily high-resolution-blended analyses for sea surface temperature. J. Climate, 20, 5473-5496, https://doi.org/10.1175/2007JCLI1824.1.

Riser, S. C., D. Swift, and R. Drucker, 2018: Profiling floats in SOCCOM: Technical capabilities for studying the Southern Ocean. J. Geophys. Res. Oceans, 123, 4055-4073, https:// doi.org/10.1002/2017JC013419.

Roemmich, D., S. Riser, R. Davis, and Y. Desaubies, 2004: Autonomous profiling floats: Workhorse for broad-scale ocean observations. Mar. Technol. Soc. J., 38, 21-29, https://doi.org/ 10.4031/002533204787522802.

Schlichtholz, P., 2011: Influence of oceanic heat variability on sea ice anomalies in the Nordic Seas. Geophys. Res. Lett., 38, L05705, https://doi.org/10.1029/2010GL045894.

_ , and M.-N. Houssais, 2011: Forcing of oceanic heat anomalies by air-sea interactions in the Nordic Seas area. J. Geophys. Res., 116, C01006, https://doi.org/10.1029/2009JC005944.

Smedsrud, L. H., R. Ingvaldsen, J. E. Ø. Nilsen, and Ø. Skagseth, 2010: Heat in the Barents Sea: Transport, storage and surface fluxes. Ocean Sci., 6, 219-234, https://doi.org/10.5194/os-6-2192010. 
and Coauthors, 2013: The role of the Barents Sea in the Arctic climate system. Rev. Geophys., 51, 415-449, https:// doi.org/10.1002/rog.20017.

Smith, D. M., R. Eade, and H. Pohlmann, 2013: A comparison of full-field and anomaly initialization for seasonal to decada climate prediction. Climate Dyn., 41, 3325-3338, https:// doi.org/10.1007/s00382-013-1683-2.

Sorteberg, A., and B. Kvingedal, 2006: Atmospheric forcing on the Barents Sea winter ice extent. J. Climate, 19, 4772-4784, https://doi.org/10.1175/JCLI3885.1.

Sun, C., and Coauthors, 2010: The data management system for the global temperature and salinity profile programme. Proceedings of OceanObs'09: Sustained Ocean Observations and Information for Society (Vol. 2), ESA Publication WPP-306, 8 pp., https://doi.org/10.5270/OceanObs09.cwp.86.

Tietsche, S., E. Hawkins, and J. J. Day, 2016: Atmospheric and oceanic contributions to irreducible forecast uncertainty of Arctic surface climate. J. Climate, 29, 331-346, https://doi.org/ 10.1175/JCLI-D-15-0421.1.

Vecchi, G. A., and Coauthors, 2014: On the seasonal forecasting of regional tropical cyclone activity. J. Climate, 27, 7994-8016, https://doi.org/10.1175/JCLI-D-14-00158.1.

Vinje, T., 2001: Anomalies and trends of sea-ice extent and atmospheric circulation in the Nordic Seas during the period 1864-1998. J. Climate, 14, 255-267, https://doi.org/10.1175/ 1520-0442(2001)014<0255:AATOSI >2.0.CO;2.

Volpi, D., V. Guemas, and F. J. Doblas-Reyes, 2017: Comparison of full field and anomaly initialisation for decadal climate prediction: Towards an optimal consistency between the ocean and sea-ice anomaly initialisation state. Climate Dyn., 49, 1181-1195, https://doi.org/10.1007/s00382-016-3373-3.

Winton, M., 2000: A reformulated three-layer sea ice model. J. Atmos. Oceanic Technol., 17, 525-531, https://doi.org/ 10.1175/1520-0426(2000)017<0525:ARTLSI > 2.0.CO;2.

Xue, Y., C. Wen, X. Yang, D. Behringer, A. Kumar, G. Vecchi, A. Rosati, and R. Gudgel, 2017: Evaluation of tropical Pacific observing systems using NCEP and GFDL ocean data assimilation systems. Climate Dyn., 49, 843-868, https://doi.org/ 10.1007/s00382-015-2743-6.

Yeager, S. G., A. R. Karspeck, and G. Danabasoglu, 2015: Predicted slowdown in the rate of Atlantic sea ice loss. Geophys. Res. Lett., 42, 10 704-10713, https://doi.org/10.1002/ 2015 GL065364.

Zhang, R., 2015: Mechanisms for low-frequency variability of summer Arctic sea ice extent. Proc. Natl. Acad. Sci. USA, 112, 4570-4575, https://doi.org/10.1073/pnas.1422296112.

Zhang, S., and A. Rosati, 2010: An inflated ensemble filter for ocean data assimilation with a biased coupled GCM. Mon. Wea. Rev., 138, 3905-3931, https://doi.org/10.1175/ 2010MWR3326.1.

—, M. Harrison, A. Rosati, and A. Wittenberg, 2007: System design and evaluation of coupled ensemble data assimilation for global oceanic climate studies. Mon. Wea. Rev., 135, 35413564, https://doi.org/10.1175/MWR3466.1.

Zweng, M., and Coauthors, 2013: Salinity. Vol. 2, World Ocean Atlas 2013, NOAA Atlas NESDIS 74, 39 pp. 
